\title{
Features of the Graphic Image in the Novel Season of Migration to the North
}

\section{ملامح الصورة البيانية في رواية موسم الهجرة إلى الشمال}

\section{Elrashid Yousif Mohamed Abbas}

rashid57@hotmail.com

The Department of Humanities and Social Sciences

Khalifa University of Science, Technology \& Research, Abu Dhabi

• Received: 23.05.2021 • Accepted: 11.10.2021 • Published online: 25.11 .2021

Abstract: This study dealt with the features of the graphic images in the novel Season of Migration to the North by the Sudanese writer Al-Tayeb Salih, in order to reveal the writer's use of the graphic image within the structure of the text of the novel. This study relied on the analytical descriptive approach, as the researcher analyzed the graphic images in the novel, such as: simile, metaphor, metaphor, and metonymy, in addition to referring to the features and purposes of these images. This study attempted to highlight the role of the Sudanese novel in enriching literary studies alongside the Arabic novel, and from what the researcher reached: the multiplicity of graphic images in the novel and its spontaneity and spontaneity, as well as the accuracy of photography that was consistent with the atmosphere of the novel, and its contribution to the interdependence of its texts, and tight coordination. The study also revealed the writer's linguistic skill, and the depth of his experience with life that was linked to its social, political and economic context, in addition to his employment of religious and popular legacies related to people's lives in fictional literature.

Keywords: Tayeb Salih, the novel, Season of Migration to the North, The Graphic Image

$$
\text { للكاتب السوداني الطيب صناولت هذه الدراسة ملامح الصور البيانية في رواية موسم الهجرة إلى الشمال }
$$


Elrashid Yousif Mohamed Abbas

بتحليل الصور البيانية الموجودة في الرواية مثل: التشبيه والمجاز والاستعارة والكناية، بجانب الإشارة إلى ملامح هذه الصور وأغراضها. حاولت هذه الدراسة أن تبرز دور الرواية السودانية في إثراء الدراسات الأدبية جنبًا إلى جنب مع الرواية العربية، ومما توصل إليه الباحث: تعدد

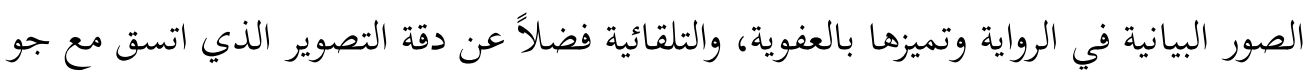
الرواية، وإسهامه في ترابط نصوصها، وإحكام تنسيقها. كما كشفت الدراسة عن مهارة الكاتب ترئب اللغوية، وعمق تجربته بالحياة التي ارتبطت بسياقها الاجتماعي والسياسي والاقتصادي، بجانب توظيفه للموروثات الدينية والشعبية المرتبطة بحياة النَّاس في الأدب الروائي، وكذلك أبانت الدراسة عمق ارتباط الكاتب ببيئه الريفية التي نشأ في ربوعها، ذلك الارتباط الذي أثر في لهي مضمون الرواية موضوع البحث. كلمات دلالية: الطيب صالح، الرواية، موسم الهجرة إلى الشَّمال، التصوير البياني

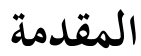
الطيب صالح، أو "عبقري الرواية العربية" كما جرت تسميته على لسان بعض النقاد، هو أديب وروائي من السودان، ولد في اليوم الثاني عشر من شهر يوليو من العام 1929م وتوفي في ليلة الأربعاء لليوم الثامن عشر من شهر فبراير من العام 2009 م في العاصمة البريطانية لندن كانت الفترة التي عاشها الطيب صالح ما بين 1929م و2009م حافلة بالكثير والمثير من. الأحداث؛حيث بدأ رحلة انطلاقه في هذه الحياة باكرًا عندما انتقل من كرمكول (مسقط رأسه) إلى الخرطوم (عاصمة السودان)؛ لإكمال دراسته الجامعية فحصل على درجة البكالوريوس في العلوم، ثم سافر إلى إنجلترا لدراسة الشؤون الدولية السياسية. تنقل الطيب صالح بين عدة مواقع مهنية؛ إذ عمل في القسم العربي لهيئة الإذاعة البريطانية، وترقّى فيها حتى وصل إلى منصب مدير قسم الدراما، واستقال منها عائدًا إلى السودان؛ ليعمل في الإذاعة السودانية، ثم تركها مهاجرًا إلى دولة قطر ؛يعمل وكيلاً في وزارة الإعلام القطرية، ومن ثم شغل 
Elrashid Yousif Mohamed Abbas

منصب المدير الإقليمي بمنظمة اليونسكو في باريس، كما عمل ممثلاً لهذه المنظمة في منطقة الخليج العرب.(Al-Fayyā, 2010) إن حالة الترحال بين الشرق والغرب والشمال والجنوب أكسبت الطيب صالح خبرة واسعة بأحوال الحياة والعالم، وأهم من ذلك أحوال أمته وقضاياها، وهذا ما وظفه في كتاباته وأعماله الروائية؛ فقد كتب عددًا من الروايات منها: عرس الزين، مريود، دومة ودحامد، ضو البيت، منسي، وموسم الهجرة إلى الشمال التى ترجمت إلى عدة لغات، ومن ثم فقد تم تتويجه بلقب (عبقري الرواية العربية) في العام 2001م، وقد ظل بفضل هذا التتويج محل حب وإعجاب عظيمين من قبل النقاد وجماهير القراء. (Al-Fayyā, 2010) ويُعدُّ الطيب صالح واحدًا من جيل الحداثيين، الذين خرجوا على رؤية الرواية التقليدية وتقنياتها؛ فقد تجاوز خطابهم الروائي المفاهيم التقليدية حول الرواية في عصورها الكلاسيكية والرومانسية؛ وتداخلت أساليبهم مع تداخلات العالم الخيالي والصوفي والواقعي والتاريخي، مما جعل رواياتهم سواء في حبكتها أو شخوصها، أكثر تعقيدًا وأعمق تركيبًا. فروايته موسم الهجرة إلى الشمال، تصف الصلة بين الشرق والغرب في قصة مصطفى سعيد(بطل الرواية) ذلك الشاب الذي ترك بلده مهاجرًا من أجل العلم منذ الثانية عشرة من عمره متنقلاً ما بين القاهرة ولندن (محطته الأخيرة)، والتي قضى فيها شطرًا من حياته ظانًا أنه جاءها غازيًا لا طالب علم، "نعم يا سادتي، إنني جئتكم غازياً في عقر داركم" (Salih, 1999)، فعاش فيها حياة اللهو والعيث الجنسي ، وبسبب ذلك وقعت بعض الفتيات الأوربيات فريسة له؛ مما أدى إلى انتحار ثلاث منهن، وموت الرابعة مقتولة على يديه، فهي رواية تصور الصراع بين الشرق والغرب، وكذلك نظرة الغرب المتقدم للشرق المتخلف؛ لذا نجدها قد نالت إعجاب 
Elrashid Yousif Mohamed Abbas

فهذا الأديب المصري (رجاء النقاش) يعبر عن سر افتنانه برواية موسم الهجرة إلى الشمال

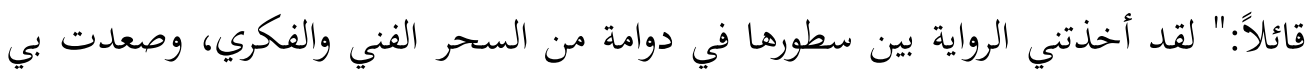
إلى مرتفعات عالية من الخيال الفني الروائي العظيم، وأطربتني طربًا حقيقيًا بما فيها من غزارة شعرية رائعة" (Al-Fayyā, 2010) .كما أنّه يصف لغتها بأنها ليست وسيلة لنقل الفكرة أو

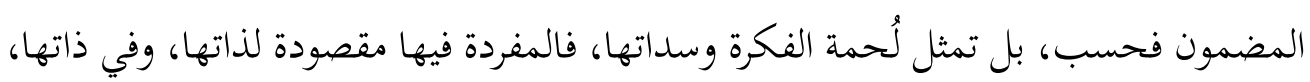
وذلك بقدر ما تثيره في النفس من رؤى وظلال، وما تبعثه من إيحاءات، فهي لغة ناصعة،

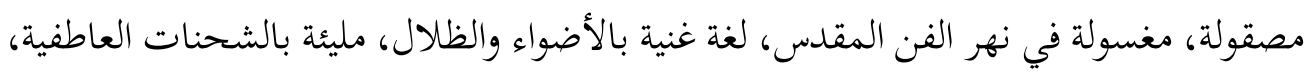
بعيدة عن التبذير والثرثرة (Al-Fayyā, 2010).

ومن جانب آخر يعبر جابر عصفور عن إعجابه ودهشته، قائلاً: "لا أزال أذكر مشاعر

الإعجاب الغامة التي انتابني عندما قرأت (موسم الهجرة إلى الشمال) للمرة الأولى، فقد

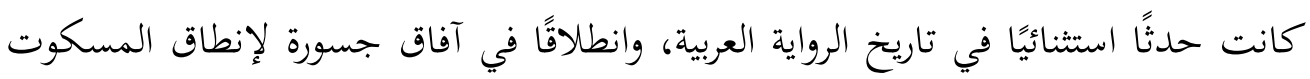
عنه في الثقافة العربية التي لا تزال تقليدية في مجملها؛ فموسم الهجرة رواية بعيدة عن التقليد

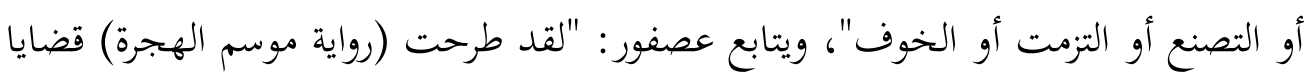

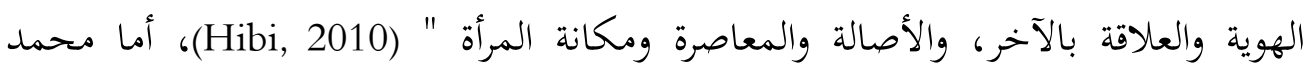
وهيبي (2010) يقول عنها:" إنّ الطيب صالح في رائعته موسم الهجرة إلى الشمال، أظهر وعيًا شموليًا لمشاكل المجتمع العربي وقضاياه المختلفة: اجتماعيًا واقتصاديًا وسياسيًا وتاريخيًا،

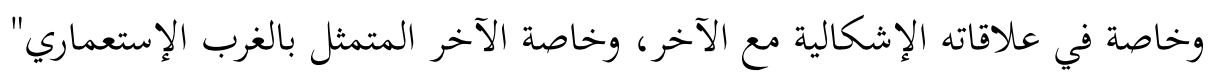
تلك الشهرة وذلك الإعجاب جعلا من الرواية مصدرًا لكثير من الدراسات والبحوث،

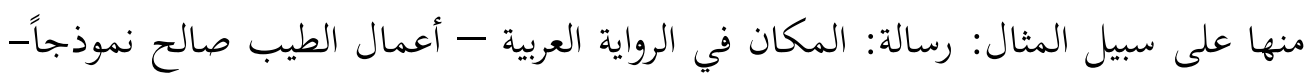

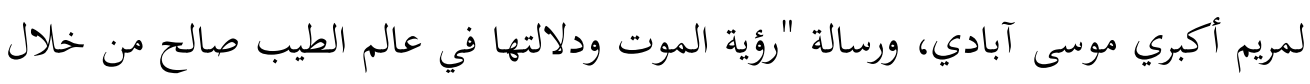


Elrashid Yousif Mohamed Abbas

روايتي: موسم الهجرة إلى الشمال وبندر شاه، لعبدالرحمن عبدالرؤوف الخانجي، وبحث"التماسك النصي في رواية موسم الهجرة إلى الشمال" لبكري الحاج، ومراد مبروك، وكتاب" شكل التعبير الديني فى روايات الطيب صالح" لإبراهيم محمد زين، و"الأنا والآخر في رواية موسم الهجرة إلى الشمال" للكاتب محمد هيبي، ورامي أبو شهاب في بحثه "الطيب صالح شكلانية الموت: قراءة في موسم الهجرة إلى الشمال بين الاستثناء والامتلاء"، ورسالة "سلوك الرجل والمرأة في رواية موسم الهجرة إلى الشمال"، لفراس حج محمد، و "علاقة الأنا والآخر في موسم الهجرة إلى الشمال"، لمحمد رُشد، كما أنَّ الناقد إدوارد سعيد جعلها أساسًا لكتابه"فيما بعد الاستشراق"... وغيرها من الدراسات والبحوث والمقالات .

فالطيب صالح كثيرًا ما يعمد في تعبيراته إلى الصور البيانية من: تشبيه، ومجاز، واستعارة، وكناية؛ من أجل إضفاء البهجة والحيوية والجمال على كتاباته، وبما أن الصور البيانية تأتي منوعة وملائمة للحدث والموقف، فهي تؤدي برموزها وأبعادها تفسيرات للنص؛ ففي مشاهد كثيرة من روايته (موسم الهجرة إلى الشمال) يأتي بوصف شخصياتها مقرونًا بوصف المكان ؛ لذا عادة ما تكون هذه الاستعارات، وتلك التشبيهات صورًا يستوحيها الطيب صالح من عناصر البيئة المحيطة به.

فدراسة الرواية لها مكانة في الحياة الأدبية توازي قراءة الرواية نفسها، فالعلاقة بينهما لا يمكن فصلها؛ فكتابتها تجربة نظرية تعبر عن رؤية الكاتب، أما دراستها فنشاط عملي يفسر ويوضح ويجلي تلك الرؤية، ومن هذا المنطلق يستخدم الباحث المنهج الوصفي التحليلي الذي يقوم على تأصيل الصورة البيانية من خلال ما تفضلت به دراسات النقد الأدبي في إطارها النظري، ومن ثم الكشف عن هذه الصور في رواية موسم الهجرة إلى الشمال. و يهدف هذا البحث إلى إظهار براعة الكاتب في توظيف الصورة داخل بنية نص الرواية، والكشف عن 
Elrashid Yousif Mohamed Abbas

قدرة الرواية السودانية في إثراء الدراسات الأدبية جنبًا إلى جنب مع الرواية العربية، وإظهار قدرة الصورة البيانية في ترابط نصوص الرواية وإحكام تنسيقها، كما تسعى إلى معرفة تأثير بيئة الراوي في مضمون الرواية، ومعرفة إمكانية توظيف الموروثات الدينية والشعبية المرتبطة بحياة النَّاس

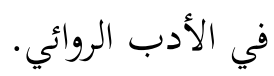

\section{منهجية البحث}

يسلك الباحث في هذه الدراسة المنهج الوصفي التحليلي ، الذي يقوم على الاستقراء والتتبع لأنماط الصورة البيانية وصولاً لتحليل الملمح الذي ينشده الراوي من خلالها.

\section{نتائج الدراسة وتحليلها}

تطورت الرواية العربية خلال القرن الماضي تطورًا ملحوظًا، واستقطبت اهتمام القراء والنقاد على اختلاف مشاربهم واتجاهاتهم، ولم تزد مكانتها إلا تأكيدًا ولاسيما في النصف الثاني من القرن الماضي، كما تنوعت تقنياتها وأساليب كتابتها، واختلفت أشكالها وتعددت احتباد أنواعها وتياراتها، حتى صارت تستحق نعتها بديوان العرب الجديد على غرار الشعر الذي ظل ديوان العرب طيلة قرون عديدة (Saeed, 2015).

لقد قاد ذلك التطور في السرد الروائي الباحثين والنقاد إلى التوسع في مصطلحه، فزيتوني يقول:"السردية تعني علم السرد بما هو مختلف عن سواه، وبما هو مؤتلف فيه ومطرد في بناء

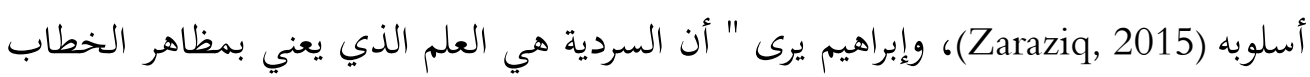

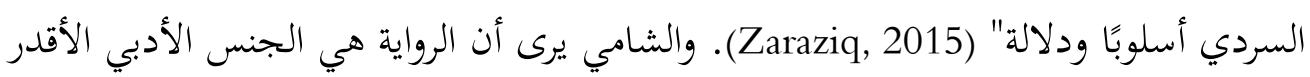
على إلتقاط الأنغام المتباعدة المتنافرة المركبة المتغايرة الخواص لإيقاع عصرنا، ورصد التحولات

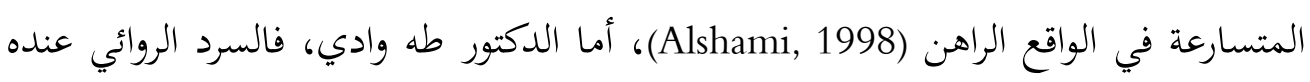

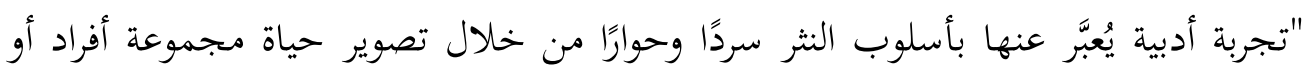


Elrashid Yousif Mohamed Abbas

شخصيات يتحركون في إطار نسق اجتماعي محدد الزمان والمكان، ولها امتداد كمي معين يحدد إنها رواية"(Wadi, 2014).

وعند ألبيريس الرواية هي "سرد قصة لا تعدو أن تكون شيئًا من نتاج المخيلة، أو حكاية

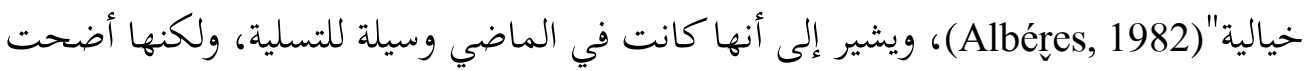
في منتصف القرن العشرين تعبيرًا عن القلق والسرائر والمسؤوليات؛ وبذا صارت تمثل من الناحية الاجتماعية أداة الاتصال الأدبي بين الجماهير المتفاوتة فيما بينها أشدَّ التفاوت، الأمر الذي ولني

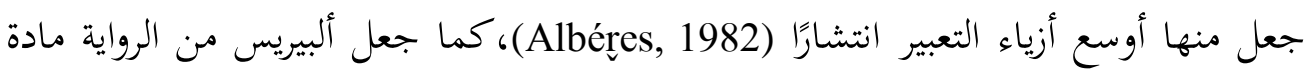
دسمة تجد فيها المجتمعات الإنسانية مبتغاها حين قال: " تقدم للجميع المتع الطفولية التي تثيرها القصة المؤثرة والمغامرة والحكاية" (Albéres, 1982)، وهي عنده تقوم بدور الكاهن، والمشرف السياسي، وخادمة الأطفال، وصحفي الوقائع اليومية، والرائد، ومعلم الفلسفة، ويري إلبيريس أن قيامها بهذه الأدور هدفه أن تحل محل الفنون الأدبية جميعها. ومن زاوية أخرى يُنظر إلى الرواية على أنَّها قصة خيالية نثرية طويلة؛ وهي من أشهر أنواع

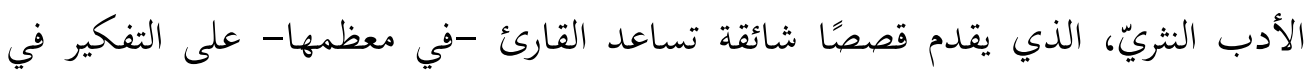
القضايا الأخلاقية والاجتماعية أو الفلسفية، كما يحث بعضها على الإصلاح، ويهتم بعضها الآخر بتقديم معلومات عن موضوعات غير مألوفة، وتكشف جوهر المألوف، ومنها ما يكون هدفه مجرد الإمتاع والتَّسلية. التصوير البياني في النقد الأدبي شغلت دراسة الصورة البيانية ميدانًا واسعًا من اهتمامات النقد العربي قديمًا وحديثًا، واختلفت الاتجاهات بين ناقد متأثر بالتراث العربي وبين آخر حاول الإفادة مما درسه وتوصل إليه النقاد الغربيون بشأن الصورة وأهميتها وعناصر تكوينها، وحاول آخرون التوفيق في موضوع الصورة بين ما خلفه لنا الأجداد من إرث نقدي وبلاغي وبين الدراسات الحديثة عند الغرب ووقوفهم على مسائل مهمة لا غنى للباحث عنها. 
Elrashid Yousif Mohamed Abbas

ونجد في تراثنا الخالد أوصافًا مختلفة للصورة البيانية، لقد عبر عنها القرآن الكريم في

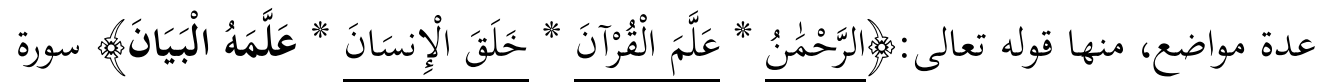
الرحمن:1-4، فالبيان يعني النطق الذي يتميز به الإنسان دون غيره من المخلوقات على حد

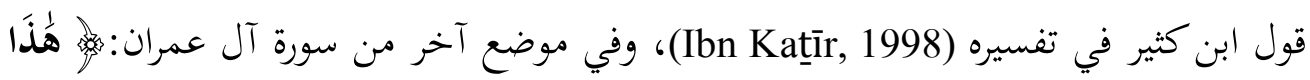

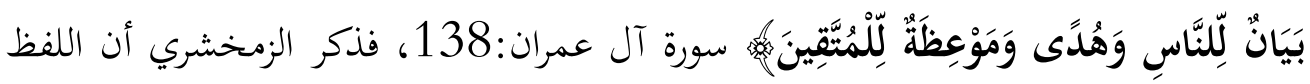

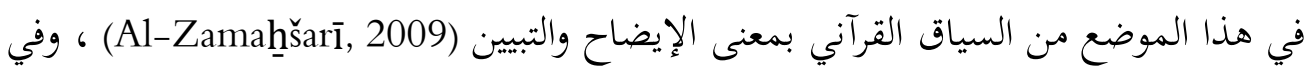

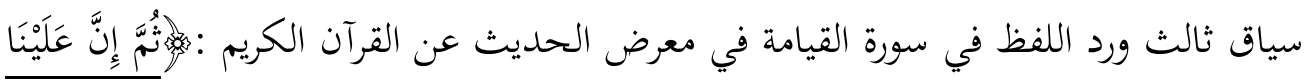

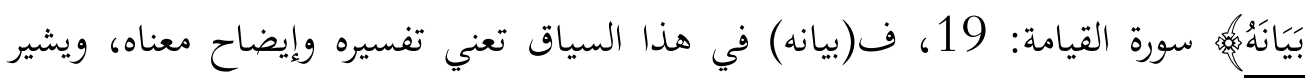

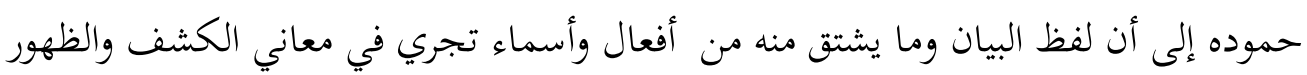
والإيضاح والإعلام، وهذه المعاني الواردة في استعمال القرآن هي ذات المعاني التي يجري عليها الاستخدام اللغوي العام للفظ البيان (Hammouda, 1996). عند القدماء، فالبيان عند

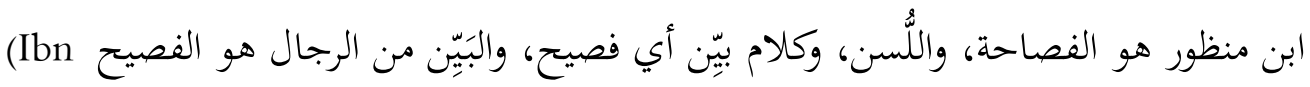

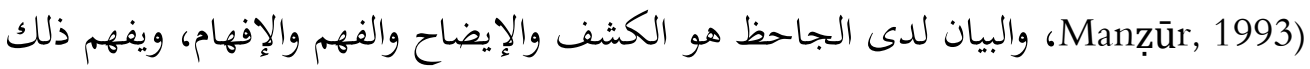
من قوله:"البيان اسم جامع لكل شيء كشف لك قناع المعنى وهتك الحجب دون الضمير حتى يفضي السامع إلى حقيقته"(Ibn Al-ğāḥiz, 2006)، أما الرماني فالبيان عنده هو الكلام الذي يظهر التمبيز بين الأشياء (Hammouda, 1996). ومن هذه المعاني اللغوية عرّف الأقدمون البيان على أنه: العلم الذي يُعرَف به إيراد المعنى الواحد بطرق مختلفة

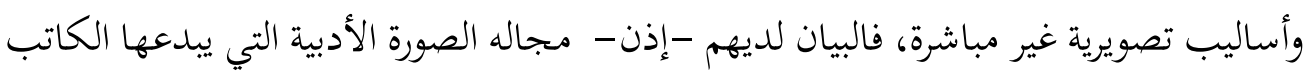
ليعبر بها عن المعنى المراد تعبيرًا وصفه روبرت فروست بقوله: " أن تقول شيئًا وتعني شيئًا

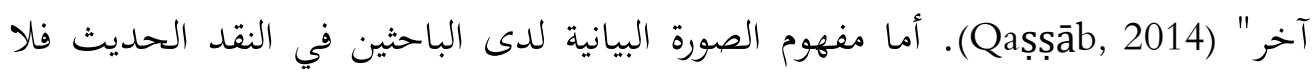
يختلف كثيرًا عن سابقيهم، حيث تعددت تعريفاتهم بتعلد رؤى النقاد والباحثين واختلاف

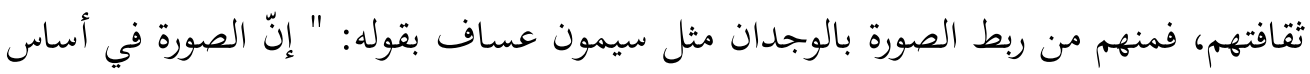

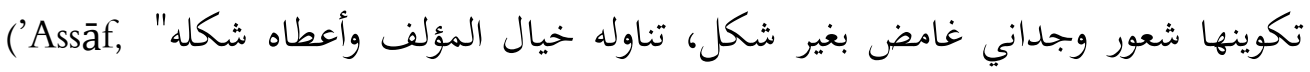


Elrashid Yousif Mohamed Abbas

(1982، وأشار إليها إسماعيل بقوله: " الصورة تركيبة وجدانية تنتمي في جوهرها إلى عالم الوجدان أكثر من انتمائها إلى عالم الواقع"(Esmail, 1981) . ومنهم من ربط مصطلح الصورة بشكلها مثل البطل الذي قال: " الصورة تشكيل لغوي يكونها خيال المؤلف من عدة معطيات يقف العالم المحسوس في مقدمتها، فأغلب الصور البيانية مستمدة من الحواس" (Al-Bațal, 1981)، ومنهم من عدها تشكيلاً عقليًا مثل عبدالقادر الرفاعي الذي أشار إلى أن " الصورة في المفهوم الفني أي هيئة تثيرها كلمات

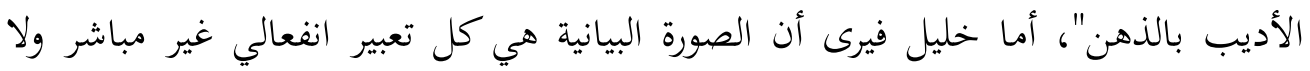
حرفي (Khalil, 1989). لقد اختلف مفهوم الصورة في النقد العربي بناء على اختلافات أصحابها واجتهاداتهم ومصادرهم التي استقوا منها غير أن كل من تحدث منهم عن الصورة

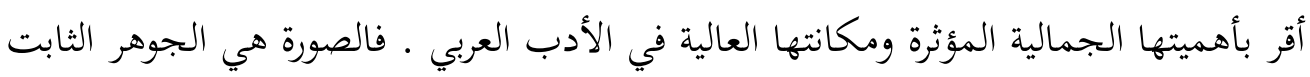

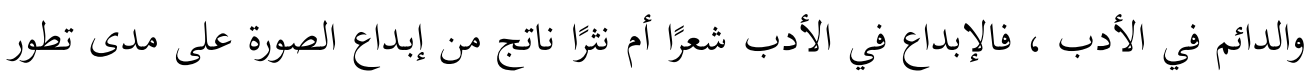

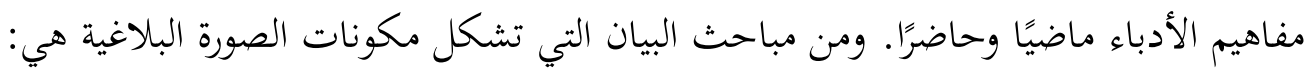
التشبيه، والاستعارة، والمجاز، والكناية، ويروم الباحث في هذه الورقة تتبع مساراتها في

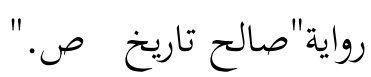
الصور التشبيهية في الرواية: يقول ابن فارس في مقاييسه: الشين والباء والهاء أصل واحد يدلُّ على تشابه الأشياء،

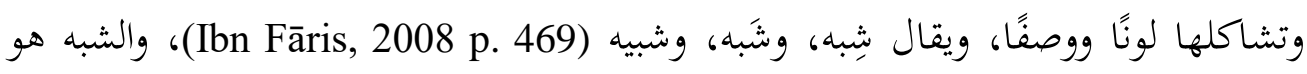

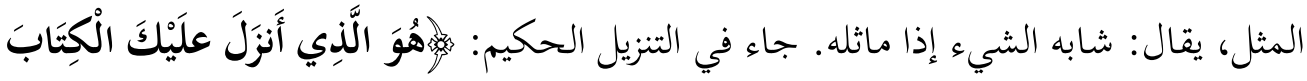

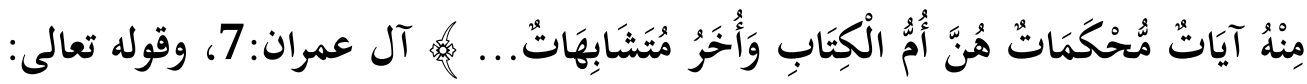

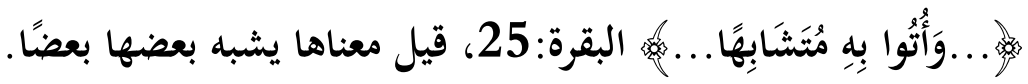

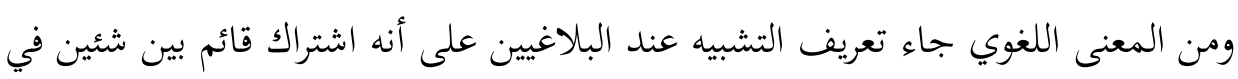

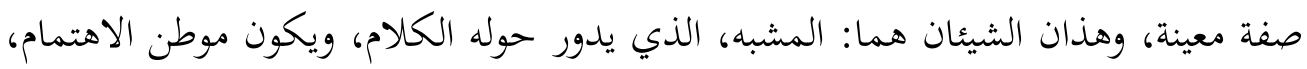

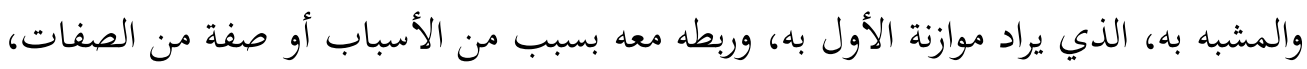


Elrashid Yousif Mohamed Abbas

وهذه الصفة تُدعى وجه الشبه، وقد تكون ثمة أداة توضح ذلك الربط، وتسمى أداة التشبيه،

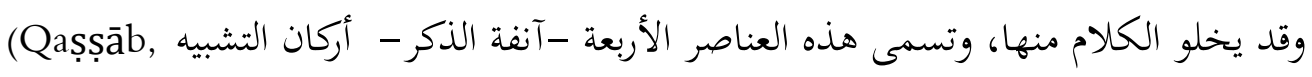

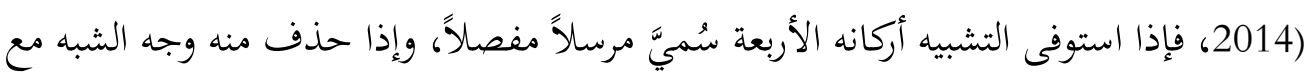

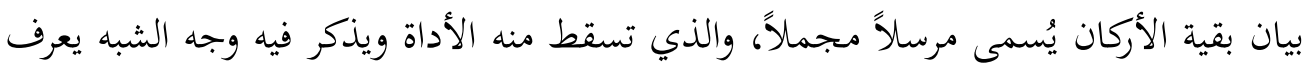
بالتشبيه المؤكد المفصل، أما إذا حذفت الآداة ووجه الشبه فصار التشبيه بليغًا، هذا فضلا عن تشبيهين آخرين، هما: التشبيه الضمني، وهو الذي لا يصرح بطرفيه الأساسيين(المشبه والمشبه

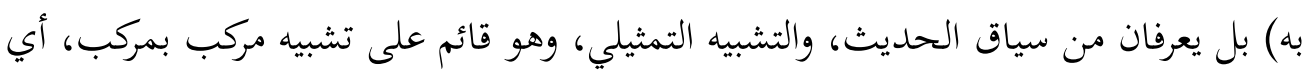

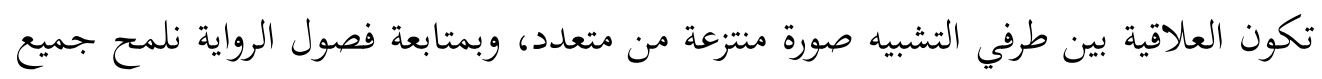

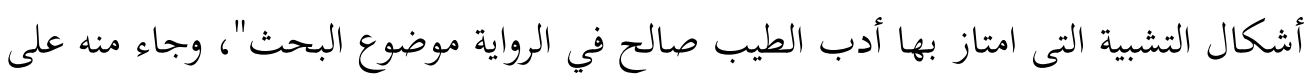

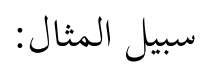

قال الطيب صالح واصفًا إحساسه وسط أهله بعد أن عاد إليهم من بعثته الدراسية: "ولم يمض وقت طويل حتى أحسست كأن ثلجاً يذوب في دخيلتي". (Salih, 1999 p.5)، هذه

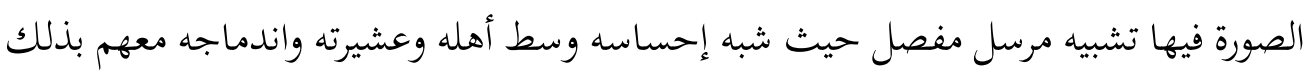
الثلح الذي يذوب في داخله، وهذه التشبيه يكشف عن الحب المتبادل بين الكاتب وأهل بلده.بل ورجوع الشيء إلي أصله مرة أخرى ومدى الترابط بينهما.

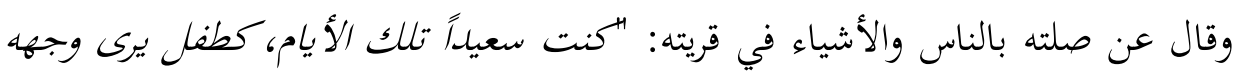
في المرآة لأول مرة" (Salih, 1999 p.8) وهذا التشبيه يؤكد إحساس الكاتب الصادق تجاه

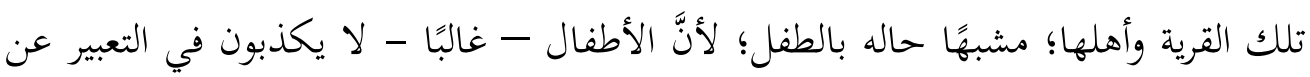
إحاسيسهم. "عقلي يعض ويقطع كأسنان محراث " (Salih, 1999 p.31)، و" كان عقلي كأنه ملدية حادة" (Salih, 1999 p 38)، في هاتين العبارتين يشبه الكاتب على لسان بطل الرواية (مصطفى سعيد) عقله بأسنان المحراث، والمدية بجامع سرعة البت في الأمر في كل، فالتشبيه 
Elrashid Yousif Mohamed Abbas

مرسل مفصل، أراد منه الكاتب الكشف حدة ذكاء بطل روايته. وملمح ذلك يشيير إلى احتقار مصطفى سعيد أقرانه في المدرسة بسبب الاختلافات الذهنية بينه وبينهم.

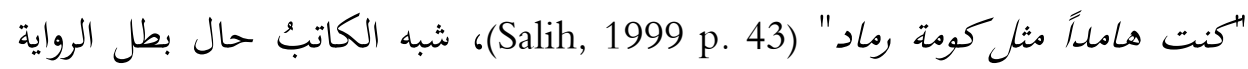
(مصطفى سعيد) ساعة محاكمته في عدة جرائم، وهو يستمع إلى مرافعة شاهد الدفاع عنه

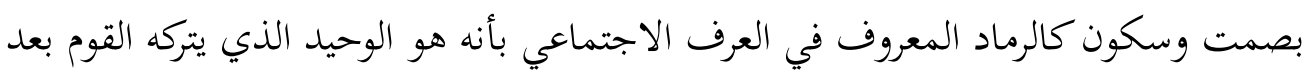
رحيلهم عن الديار؛ لأنه لا نفع له.

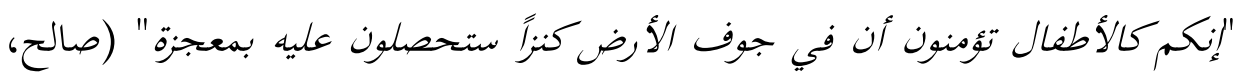

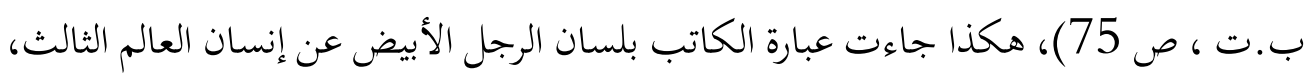

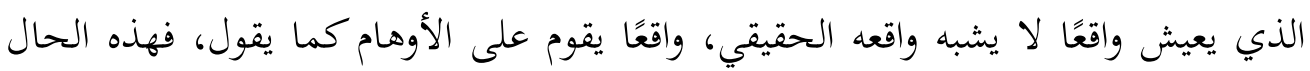

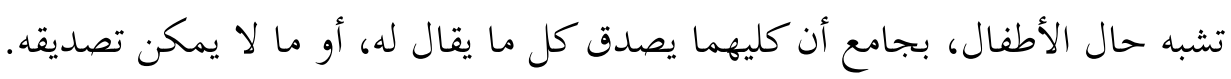

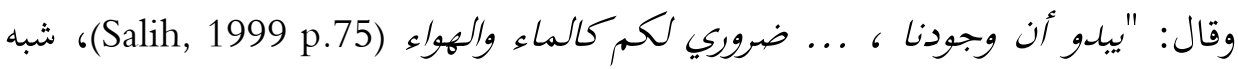

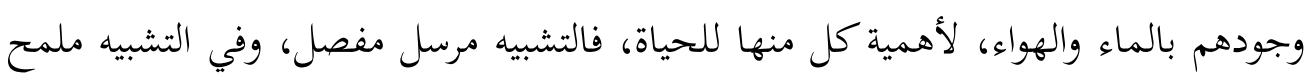

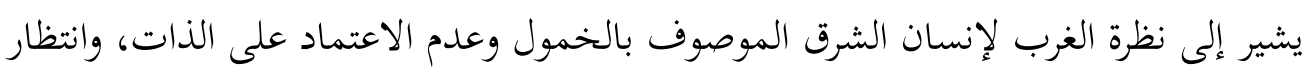
الانجازات من الغرب، فهذا التشبيه والذي سبقه غرضهما اظهار عدم قدرة المجتمع الشرقي

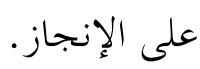

قال الطيب صالح في وصف ديوان بطل الرواية (مصطفى سعيد): "ستفها لم يكن.

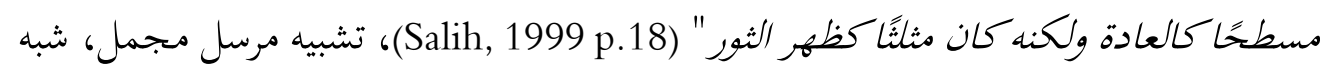

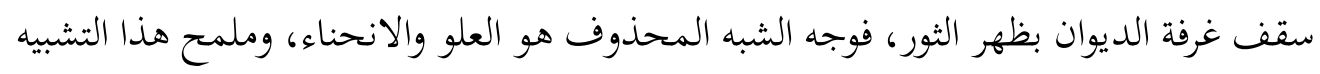

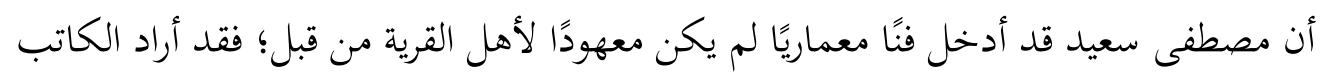
أن يظهر تأثر الحضارة السودانية بالحضارة الغربية في هيئة المباني وشكلها.

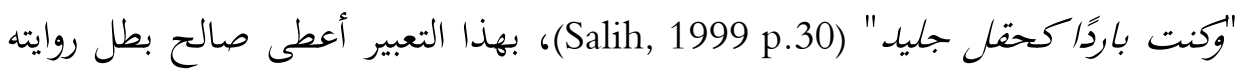

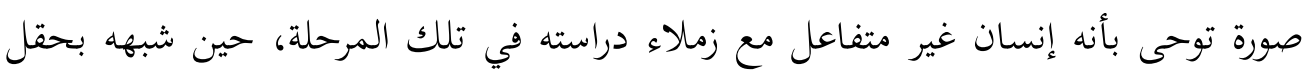
الجليد في البرود، الذي يوحي بعدم الاستجابة والتفاعل مع الآخرين. 
Elrashid Yousif Mohamed Abbas

"والأصوات لها وقع نظيف في أذني، مثل حفيف أجنحة الطير" (Salih, 1999 p.37)، وصف صالح لأصوات الناس والأشياء في لندن بحفيف أجنحة الطير فيه تشبيه مرسل مجمل، حُخِف منه وجه الشبه، وهو الهدوء في كل، وملمح هذا التشبيه يشير إلى اكتشاف الفرق الشاسع بين ضجيج القاهرة - محطته الأولى - وهدوء لندن - محطنه الثانية-، تشبيه قصد ولهد منه الإشارة إلى الفرق بين الثقافتين، ثقافة الشرق التي تكثر من الضوضاء والضجيج، وثقافة الغرب التي تحب الهدوء والسكينة. "وجهي عربي كصحراء الربع الخالي" (Salih, 1999 p.50)، تشبيه مرسل مجمل، حيث وليث شبه بطل الرواية وجهه بصحراء الربع الخالي، التي اشتهرت بقسوة البيئة الطبيعية وخلوها من

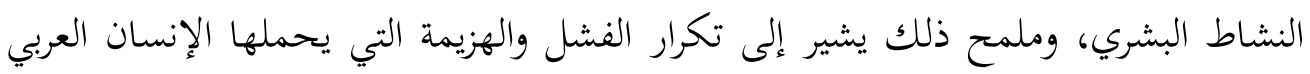
منذ بدايات مشاريع النهضة والاستقلال والحداثة، خصوصًا أنها ظهرت في مرحلة انكسار التيار القومي العربي عقب فشل وحدة مصر مع سوريا 1961م وحرب اليمن 1967م.

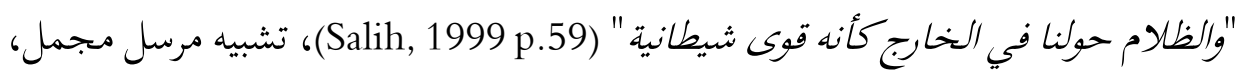
شبه الظلام بالشيطان، بجامع إشاعة الرعب والخوف في كل من المشبه والمشبه به.وملمح هذا التشبيه يبين واقع الحياة في الريف السوداني الذي يكسو الظلام شوارعها ليلاً.

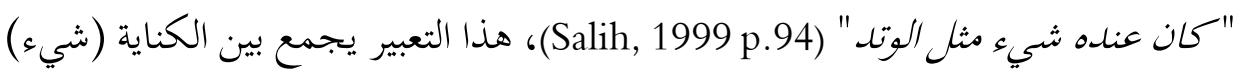

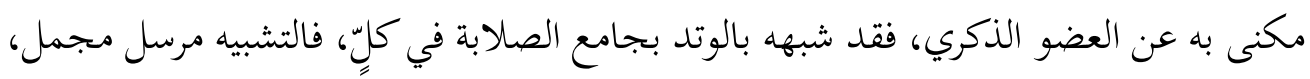

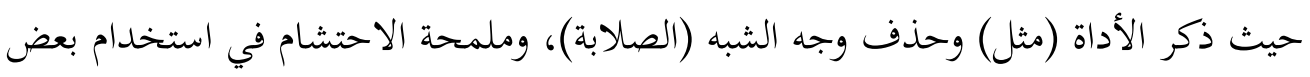
العبارات الدالة على أعضاء الذكورة استخدامًا مباشرًا.

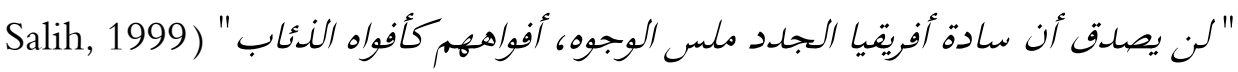

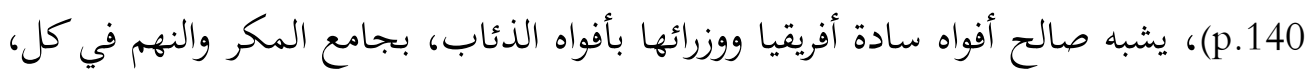

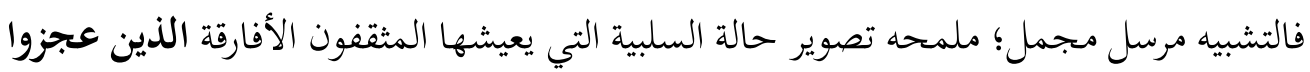
عن ممارسة أي تأثير ذي مغزى على تقدم شعوبهم.بعد خروج المستعمر من بلادهم. 
Elrashid Yousif Mohamed Abbas

أما صور التشبيه البليغ فتبدو في قوله: "أنت آلة صماء" (Salih, 1999 p.37)، التشبيه

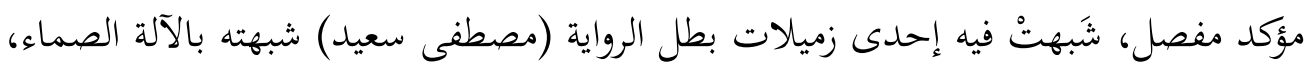
بجامع عدم الاستجابة والتفاعل في كل ، وملمح هذا التشبيه يأتي لتأكيد غرور مصطفى سعيد وعدم تفاعله مع الآخرين. "أنت ثور همجي لا يكاٌُ من الطراد" (Salih, 1999 p.44)، شبهت جين مورس مصطفى

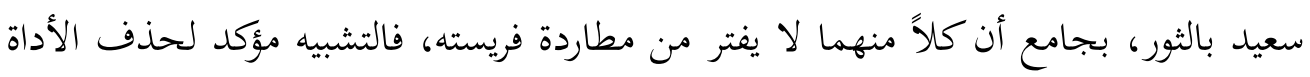
ومفصل لذكر وجه الشبه (الطراد)، وملمحه يؤكد على لهو مصطفى سعيد وولعه بالنساء. "وأنا صحراء الظمأ " (Salih, 1999 p.49)، يشبه بطل الرواية نفسه بالصحراء التي لا ماء وماء

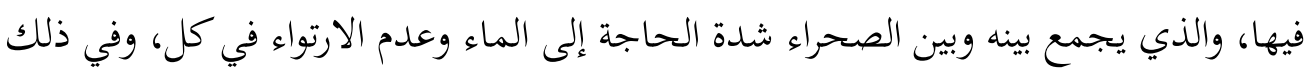
إشارة إلى نفس البطل المتعطشة دومًا لاشباع رغبته الجنسية وخاصة بما عُرف عنه من أنه زير

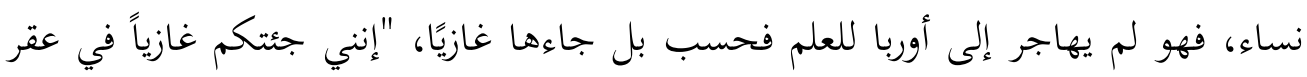

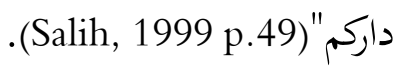

"غرفة نومي معبرة ..." (Salih, 1999 p.40)، تشبيه بليغ حيث شبه صالح على لسان بطل الرواية غرفة نومه بالمقبرة، بجامع كثرة الضحايا في كل، فقد ذهبت ثلاث حسناوات ضحية لتصرفاته الشهوانية. وملمحه يشير إلى أن علاقة مصطفى سعيد ـ بطل الرواية ـ بالمرأة هي دائمة علاقة نهايتها مأساوية. " النيل ذلك الإله الأفعى" (Salih, 1999 p.51)، تشبيه صالح للنيل بالإله الأفعى على فالى لسان مصطفى سعيد حين نجح في الإيقاع بإيزابيلا سيمور في حباله؛ فيه ملمح إلى استوحاء الكاتب هذه الصورة البيانية من الأسطورة النوبية الفرعونية التي تصور النيل إلهاّا أفعى تُعََّّم له له القرابين من الحسناوات كل عام؛ لكي يفيض ولا ينضب.

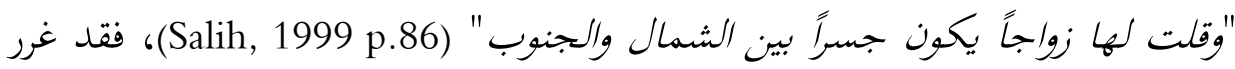
البطل بـ(آن) ابنة العشرين والتي كانت تؤمن بالفلسفات الشرقية حين شبه لها زواجه منها 
Elrashid Yousif Mohamed Abbas

بالجسر الذي يربط بين حضارتي الشرق والغرب، فالتشبيه بليغ، ملمحه يشير إلى دور الزواج

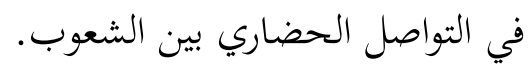
"أنتم عصب الحياة، أنتم ملح الأرض " (Salih, 1999 p.122)، تشبيه بليغ، حذفت ابت منه

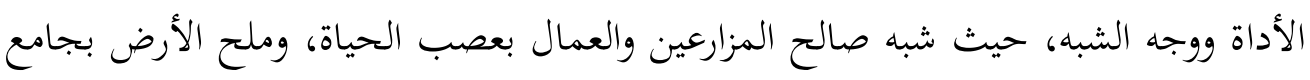

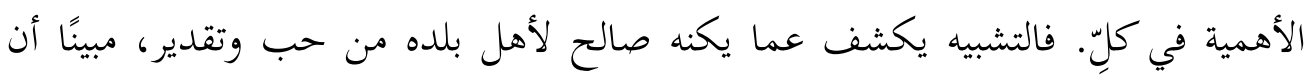
وجدوهم فَعَلَ في الحياة فِعْلَ العصبِ في المخَ، وأكسبها طعمًا كما يكسب الملح الطعام

ومن صور التشبيه التمثيلي كذلك، وصف صالح لبطل روايته قائلاً: "وحاجباه متباعدان

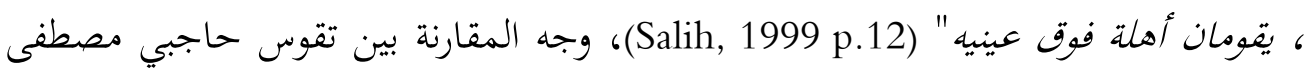
سعيد وصورة الهلال في كبد السماء، فالتشبيه بليغ. أراد منه الكاتب إضفاء نوع من الوسامة على بطل الرواية وخاصة أنه أصبح مصيدة للكثيرات من حسناوات الغرب.

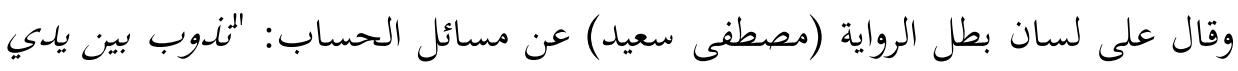

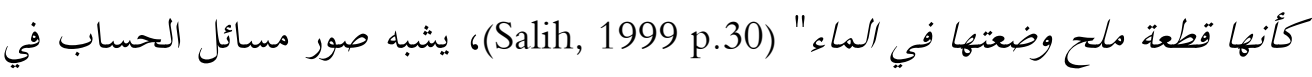
عقل بطل الرواية بصورة ذوبان قطعة الملح في الماء، فالتشبيه تمثيلي، ملمحه غرور مصطفى سعيد بذكائه.

"وفي يله مسبحته من خشب الصنلل، تلدور في حكرة دائبة كقواريس الساقية" ( Salih,

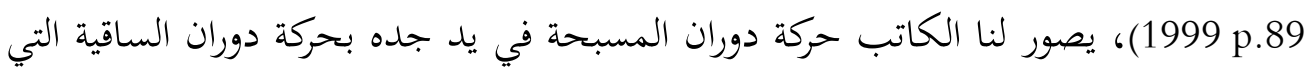

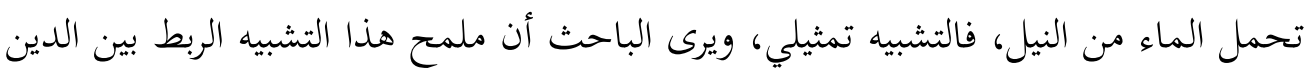

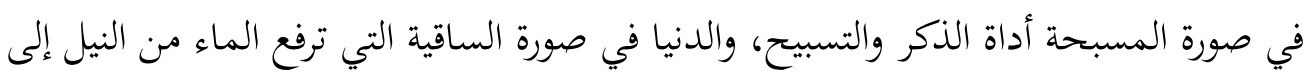

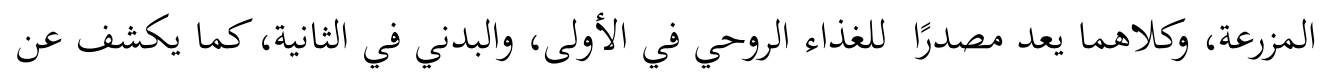
ارتباط الكاتب ببيئنه النيلية ذات العمق الديني.

"ونجوم السماء مجرد فتوق في ثوب قديم مهلهل" (Salih, 1999 p.115)، شبه صورة النجوم في السماء بصورة الفتوق الموجودة في الثوب البالي، هذا التشبيه تمثيلي، ولكنه تشبيه 
Elrashid Yousif Mohamed Abbas

مقلوب حيث كان ينبغي عليه أن يشبيه فتوق الثوب بنجوم السماء، لكن الكاتب فعل العكس، ملمحه يبين مهارة الكاتب اللغوية، وعمق تصويره للأشياء من حوله. "ثفق المغيب ليس دمًا ولكنه حناء في قدم المرأة" (Salih, 1999 p.137)، هذا التشبيه فيه صورة منتزعة من متعدد حيث شبه صورة شفق مغيب الشمس في شدة احمراره بصورة الحناء في قدم المرأة، وهذا تشبيه مقلوب حيث كان ينبغي عليه أن يشبيه صورة الحناء في

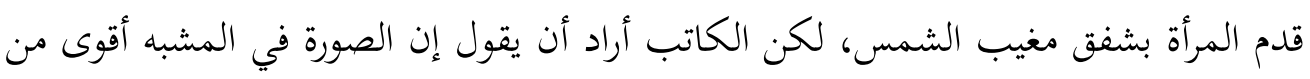

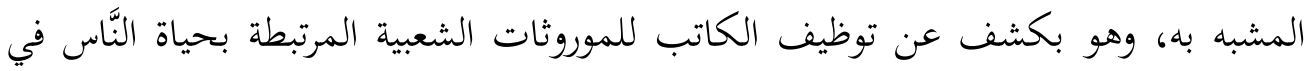

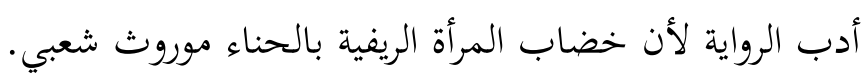
"البقر والضأن في الحقول وكأنها حصوات بيضاء وسوداء" (Salih, 1999 p.181)، شبه الكاتب صورة البقر والضان في اختلاف ألوانها وهي وسط الحقول بصورة الحصوات في ألوانها المختلفة وهي على وجه الأرض، فالتشبيه صوره منتزعة من متعدد وهذا يعد تشبيها تمثيليًا، نلمح فيه عمق ارتباط الطيب صالح ببيئه الريفية التي نشأ في ربوعها، ذلك الارتباط الذي أثر في مضمون النص. "يحيط بها حيث تكون لفيف من المعجبين يفون حولها كالنباب" (Salih, 1999 185.p)، تشبيه تمثلي؛ لأن صورته انتزعت من متعدد شبه صورة تهافت المعجبين حول (جين مورس)، بصورة قطعة الحلوى التي إلتف حولها الذباب، ملمحه إظهار جمال "جين مورس" حينما صورها بالحلوى، وشدة جاذبيتها للآخرين عندما وصف حالهم بحال الذباب الذي يجتمع حول ما يحب؛ فكأن بطل الرواية يحاول تبرير حبه لـ(جين مورس) وتعلقه بها. الصور المجازية في الرواية:

المجاز في اللغة هو التجاوز والتعدّي، وفي الاصطلاح اللغوي هو: صرف اللفظ عن معناه الحقيقي إلى معنى آخر لوجود علاقة بين المعنى الحقيقي والمعنى الجديد، وهو نوع من التعبير الفني الذي يُعصد به عرض المعاني في قالب جميل، ويصنف مع علم البيان، 
Elrashid Yousif Mohamed Abbas

والمجاز وسيلة لترسيخ المعنى وتمكينه في نفس المخاطب؛ لأنه أبلغ من الحقيقة في التعبير؛ لما يقوم به من التخييل والتجسيد(Qașsaāb, 2014).

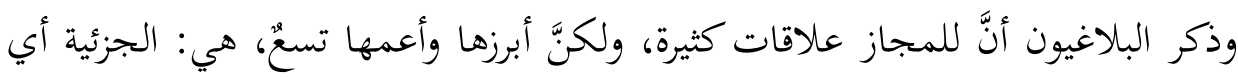

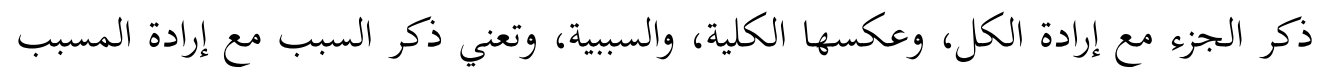
عنه، وضدها المسببية، والمحلية، وهي ذكر المحل(المكان) ويراد به الحال (موجودات المكان)، وتقابلها الحالية، واعتبار ماكان، ومعناه أن يسمي الشيء باسم ما كان عليه لا بما هو عليه حاليًا، ويقابلها باعتبار ما سيكون عليه مستقبلاً، والعلاقة الآلية، أي ذكر اللفظ الدئي مالدال

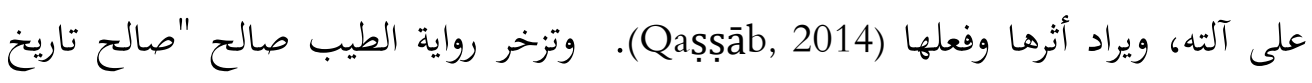
ص. إلى الشمال" بمجازات متنوعة منها على سبيل المثال قوله:

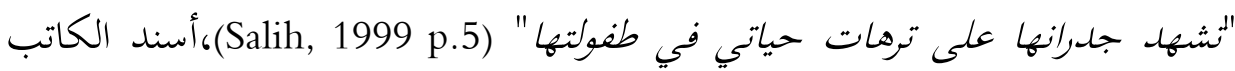

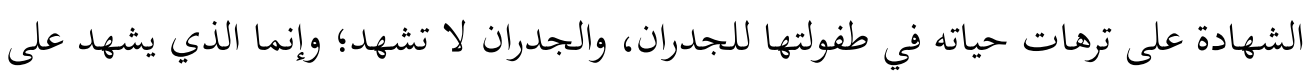
ذلك أهله وأهل قريته، فالمجاز مرسل علاقته المحلية، ملمحة شدة ارتباط الإنسان بالمكان.

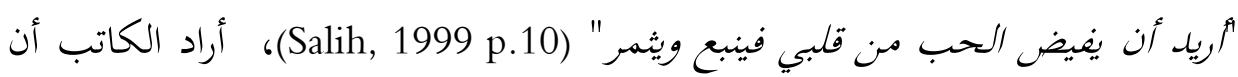
يفيض من نفسه الحب، فعبر بالقلب الذي هو جزء من النفس، أو أنه أسند الفيضان إلى لى القلب والقلب لايفيض وحده بل البدن كله، والقلب جزء من البدن فهذا مجاز مرسل علاقته الجزئية، فيه تأكيد للتسامح الذي يتصف به الكاتب تجاه الآخرين.

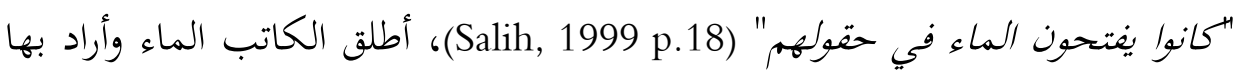
القنوات التي تجري منها الماء؛ لأن الماء لا تفتح وإنما تفتح القنوات لتنساب منها الماء. ، فالمجاز مرسل علاقته الحالية. "القاهرة ملدينة ضاحكة" (Salih, 1999 p.37)، أسند الكاتب الضحك للقاهرة، والقاهرة لاتضحك وإنما الذي يضحك هم أهلها، فهذا مجاز مرسل علاقته المحلية؛ لأنه ذكر المحل مل مله وأراد الحالين فيه، ملمحه يعكس طبيعة الشعب المصري الموسوم بروح الفكاهة والمرح، وارتباط صالح بذكرياته في القاهرة. 
Elrashid Yousif Mohamed Abbas

"شهر زاد متسولة في أنقاض ملدينة قتلها الطاعون" (Salih, 1999 p.44)، أطلق المحل(المدينة) وأراد أهلها هم الذين قتلهم الطاعون؛ لأن الطاعون لايقتل المدينة وإنما يقتل أهلها، فالمجاز مرسل علاقته المحلية.

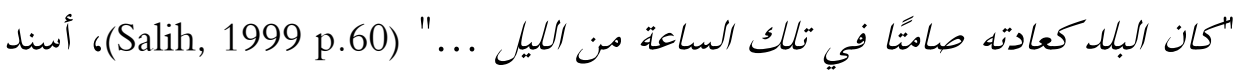
الصمت للبلد، والبلد لايصمت، وإنما يصمت أهلها، فهذا مجاز مرسل علاقته المحلية، يلمح إلى حياة الريف الهادئة ليلاً. أرجو أن تمنحني المحكمة ما عجزت أنا عن تحقيقه" (Salih, 1999 p.85)، أسند المنح للمحكمة، والمحكة لاتمنح، وإنما الذي يمنح هم قضاة المحكمة، فهذا مجاز مرسل

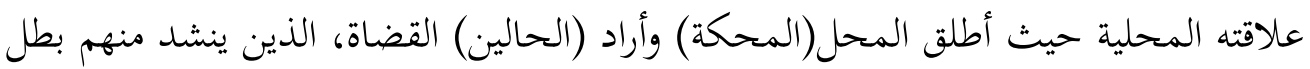
الرواية العدل، الذي عجز عن تحقيقه من خلال ممارساته مع الآخرين. "بيوت القرية ... تشرئب بأعناقها أمامنا ( (Salih, 1999 p.86)، في كلمة (بيوت القرية)

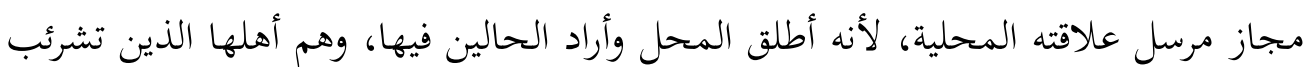
أعناقهم، ملمحه يبين طيبة أهل الريف وترحيبهم بالزائرين.

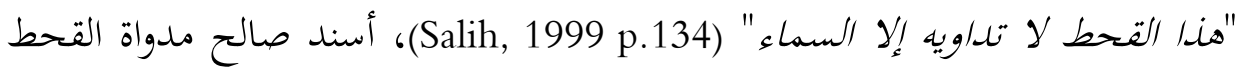
(للسماء) والسماء لاتدواي القحط وإنما الذي يداوي القحط هو (المطر)، فهذا مجاز مرسل علاقته المحلية أو المجاورة، ملمحة يبين أهمية ماء المطر لحياة الزرع رغم أنهم يزرعون بجوار نهر النيل. "وخحود صاغرات وجباه خاشعة" (183 p. Salih, 1999 )، أسند صالح كلمتي(صاغرات، وخاشعات) إلى الخدود،والجباه، فهي لا تكون صاغرات وخاشعة وحدها، وإنما يحدث ذلك

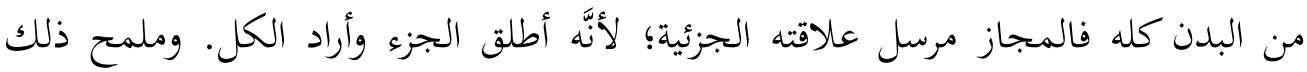
استسلام بعض حسناوات أوربا ضحية لبطل الرواية. 
Elrashid Yousif Mohamed Abbas

"في عينيها تحد ونداء" (Salih, 1999 p.186)، أطلق صالح الجزء، وهي(العيون) وأراد بها (الكل) صاحبة العيون. لأن التحدي والنداء لايمكن أن يكون من العيون وحدها بل من وناء صاحبتها بشحمها ولحمها، فالمجاز مرسل علاقته الجزئية.

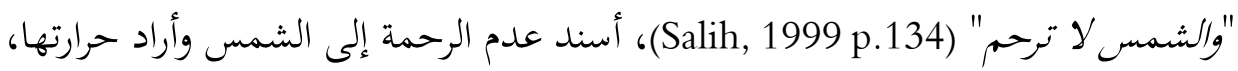
والشمس آلة الحرارة، فهذا مجاز مرسل علاقته الآلية. الصور الاستعارية في الرواية:

الاستعارة في اللغة مأخوذة من العارية: أي نقل الشيء من شخص لآخر حتى تصبح تلك العارية من خصائص المعار إليه، والعارية والعارة ما تداولوه بينهم، وقد أعاره الشيء وأعاره منه وعاوره إياه، والمعاورة والتعاور شبه المداولة، والتداول يكون بين اثنين، واستعار: طلب العارية، واستعاره منه: طلب منه أن يعيره إياه (Hammouda, 1996)، والتعريف الجامع للاستعارة عند البلاغيين هي كلمة استعملت في غير معناها الحقيقي لوجود علاقة تشبيه بين المعنى الحقيقي والمعنى المجازي، مع وجود قرينة تمنع إرادة المعنى الحقيقي، وتوجب إرادة

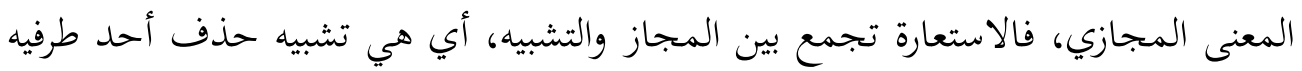
(Qaṣṣāb, 2014)، وهي تقوم على ادعاء أن المشبه هو عين المشبه به؛ لذا فهي أكثر مبالغة من التشبيه في تصوير التعبير عن الصفة، فالتشبيه يقوم على وجود فاصل بين المشبه والمشبه به، بينما الاستعارة تقوم على توحيد المشبه والمشبه به وجعلهما شيئًا واحدًا؛ مما جعلها في في لئي

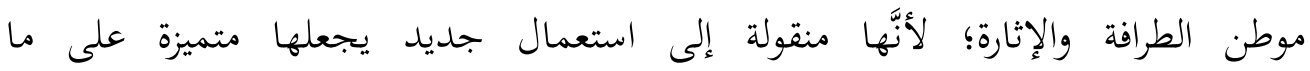

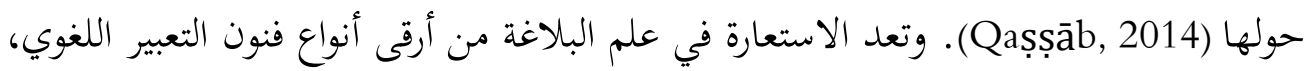

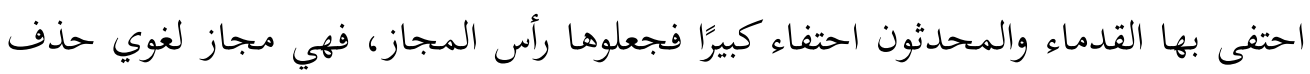
أحد طرفيه عند أكثر البلاغيين وإن كان عبدالقاهر تردد فيها، فجعلها مجازًا عقليًا مرة، ومجازًا

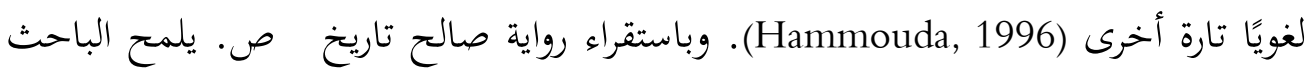

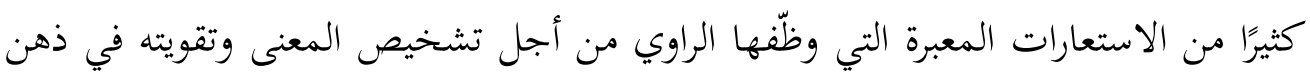

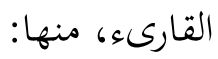


Elrashid Yousif Mohamed Abbas

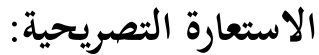

قال الطيب صالح: "ولاحظت كيف طغى الضعف في وجهه" (Salih, 1999 (S.14)، الاستعارة في كلمة(طغى) حيث شبه صالح كثرة الغضب بالطغيان، ووجه الشبه هو تجاوز الحد، وذلك في موطن بيان شدة الغضب، فالاستعارة تصريحية تبعية.

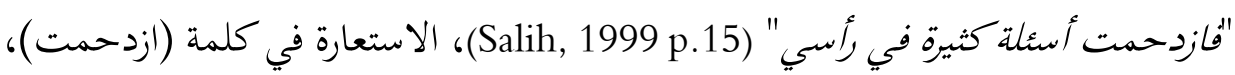
حيث شبه صالح كثرة الأسئلة بالازدحام، ووجه الشبه الكثرة وشدة التدافع، وذلك لبيان كثرت الأسئلة، فالاستعارة تصريحية تبعية. "وهاج الموج تحت السفينة" (Salih, 1999 p.36)، الاستعارة في كلمة (هاج) حيث شبه سكانه صالح حركة الموج بالهيجان، بجامع شدة الاضطراب في كل، ثم حذف المشبه وهو (حركة الموج) واستعار لفظ المشبه به (هاج) للمشبه على سبيل الاستعارة التصريحية. "وحين يبين الخيط الأبيض من الخيط الأسود" (Salih, 1999 p.78)، شبه صالح النهار بالخط الأبيض بجامع الوضوح في كل، ثم حذف المشبه وهو(النهار) واستعار المشبه به وهو(الخيط الأبيض) للمشبه على سبيل الاستعارة التصريحية، كما شبه (الليل بالخيط الأسود) بجامع انعدام الرؤية في كلٍّ، ثم حذف المشبه وهو (الليل) واستعار المشبه به وهو (الخيط

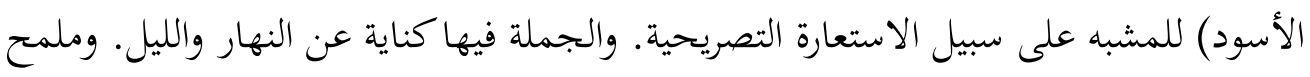
ذلك يبين قدرة الكاتب على توظيف ثقافته الدينية وتأثره بالنص

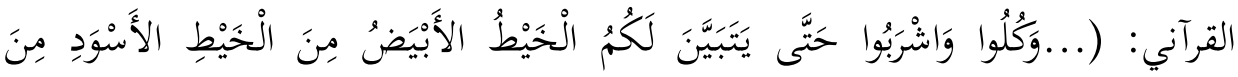

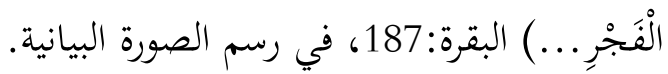

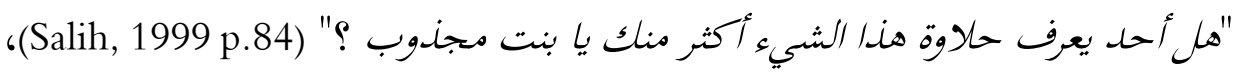

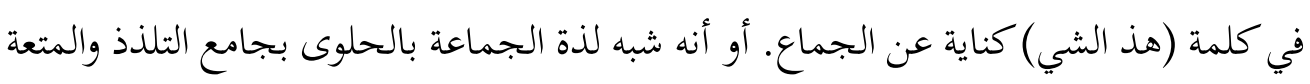
في كل، ثم حذف المشبه وهو ( لذة الجماع) واستعار المشبه به وهو (حلاوة الشيء) للمشبه، وذلك على سبيل الاستعارة التصريحية. وملمحه ثقافي؛ فثقافة المجتمع الشرقي تعد الألفاظ الدالة على المعاشرة الجنسية من المحظورات اللغوية؛ لذا لم يرد ذكرها صراحة. 
Elrashid Yousif Mohamed Abbas

"وانتشر دم المغيب فجأة في الأفق الغربي" (Salih, 1999 p.111)، شبه صالح شفق الغروب بالدم بجامع الإحمرار في كل، على سبيل الاستعارة التصريحية، يشير ذلك إلى قدرة الكاتب في توظيف عناصر الطبيعة في رسم صورته البيانية.

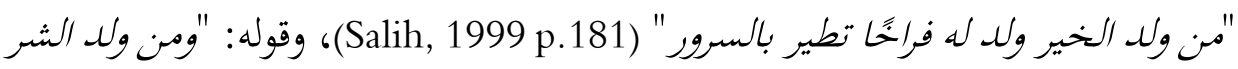
أنبت له شجرًا أشواكه الحسرة وثمره الندم" (Salih, 1999 p.182)، شبه صالح في الاستعارة الأولى عمل الخير بولادة الفراخ التي تحمل السرور، بجامع النفع في كل، وفي الاستعارة الثانية شبه عمل الشر بالولادة التي تكون ثمرتها ذات أشواك، بجامع عدم النفع في كل، فالاستعارة تصريحية في كل، ومما زاد من جمال الصورة هنا أن الاستعارتين وردتا بصيغة (المثل) وهذا يدل على قدرة الكاتب على توظيف التراث في صورته البيانية. "وبقية الوقت نقضيه في حرب ضروس" (Salih, 1999 p.191)، وصف صالح على لسان مصطفى سعيد ما ينشب بينه وبين زوجته (جين مورس) من خلافات من حين لآخر بالحرب

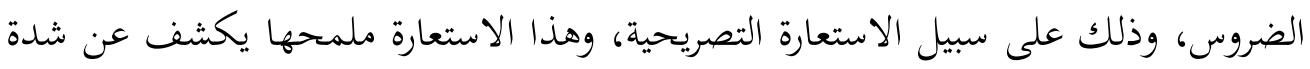
الصراع بين الشرق في شخصية مصطفى سعيد، والغرب الذي يتجسد في شخصية زوجته جين

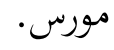
"وسنهزم الفقر" ، (Salih, 1999 p.137)، في كلمة (نهزم) استعارة تصريحية، فقد شبه القضاء على الفقر بهزيمته، وملمح هذه الاستعارة يشير إلى إراداة الإنسان السوداني في تحدى الصعاب والعمل من أجل الانتصار عليها.

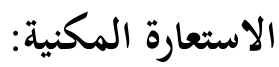

أبدع صالح في بناء صورته الفنية في هذه الرواية؛ وذلك بتوظيفه الاستعارة المكنية لتشخيص المعاني الذهنية المجردة تارة وتجسيدها تارة أخرى وإخراجها في صورة مادية محسوسة تبدو في النماذج التالية:

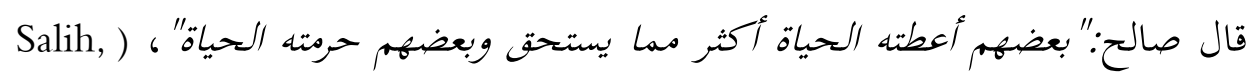

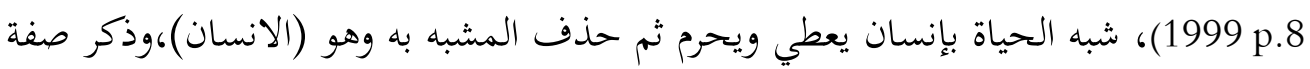


Elrashid Yousif Mohamed Abbas

من صفاته وأسندها للمشبه على سبيل الاستعارة المكنية، وملمحها الإشارة إلى الفوارق الطبقية الموجودة بين الناس حتى في دول الغرب التي هي في مخيلة إنسان الشرق خالية تمامًا من هذه الفوارق.

"تشحذ خيالي حكايات الماضي" (Salih, 1999 p.10)، الاستعارة في كلمة (خيالي)

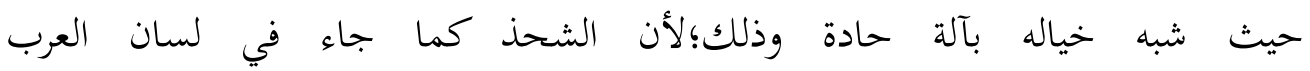

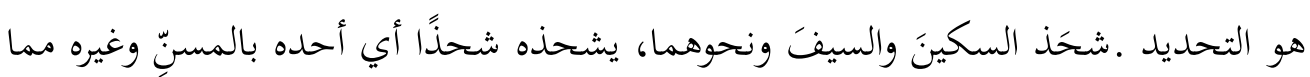

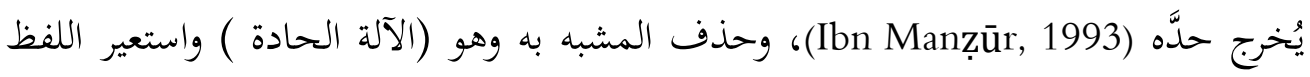
الدال على المشبه به وهو (تشحذ) على سبيل الاستعارة المكنية، والجامع بينهما أن الشحذ يجد السكين ويقويها ، كذلك حكايات الماضي تقوي الخيال. "مصطفى رجل عميق" (Salih, 1999 p.18)، الاستعارة في مصطفى، حيث شبه مصني مصطفي بالبئر العميق، ثم حذف المشبه به وهو(البئر) وذكر صفة من صفاته وهي (عميق) أو (العمق) وأسندها للمشبه على سبيل الاستعارة المكنية. فالجملة تشير إلى أن شخصية مصطفى سعيد صعيد يكتنفها الغموض.

"وأضاءت وجهه /بتسامة كبيرة" (Salih, 1999 p.33)، في كلمة (إبتسامة) استعارة مكنية، حيث شبه صالح ابتسامة الوجه بمصباح يضيء ثم حذف المشبه به وهو( المصباح) وذكر صفة من صفاته وهي (أضاءت) وأسندها للمشبه( ابتسامة وجهه) على سبيل الاستعارة المكنية. وذلك لبيان شدة الفرح التي غمرت الرجل.

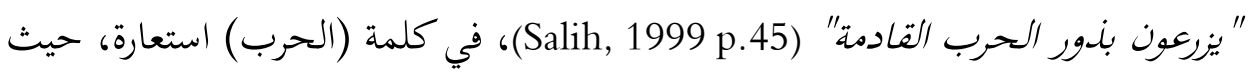
شبه صالح الحرب بالنبات، ثم حذف المشبه به، واستعير اللفظ الدال على المشبه به، وهو

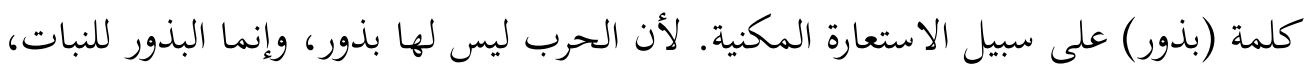
والغرض من ذلك بيان ما خلفه الأوربيون من حروب في الدول الأفريقية التي استعمروها.

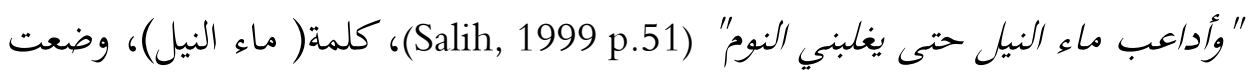

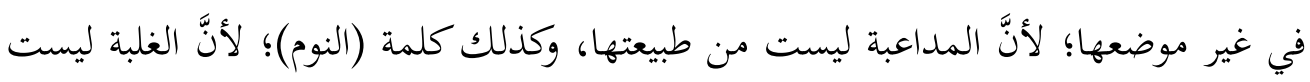


Elrashid Yousif Mohamed Abbas

من صفاتها، مما يدل على تجوز صالح في الاستعمال، وأنهما مشبهتان بمن تنطبق عليه صفة المداعبة والغلبة وهو الكائن الحي، فالاستعارة مكنية، وملمحها ارتباط وجداني بين صين صالح والنيل.

"تلامس وجهي نسمات الليل الباردة" (Salih, 1999 p.60)، في هذا التعبير استعارة مكنية حيث شبه صالح نسمات الليل الباردة وهي تمر على وجهه بيد الآدمي تلامسه، وحذف المشبه به وهو (الآدمي) وذكر صفة من صفاته وهي (تلامس) وأسندها للمشبه (نسمات الليل) على سبيل الاستعارة المكنية. "هكذا غرسوا في قلوب الناس بغضنا" (Salih, 1999 p.68)، شبه صالح البغض بالشجر

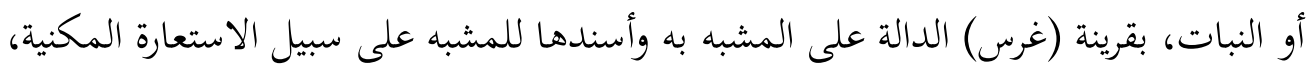

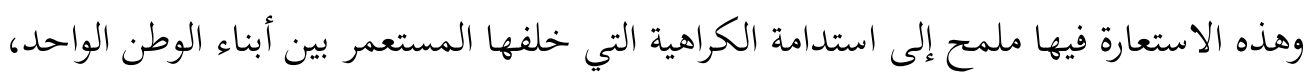
ومازلنا في السودان نقطف ثمار ذلك الغرس. "أشباح الليل تتبخر مع الفجر" (Salih, 1999 p.78)، شبه صالح ظلام الليل بالأشباح

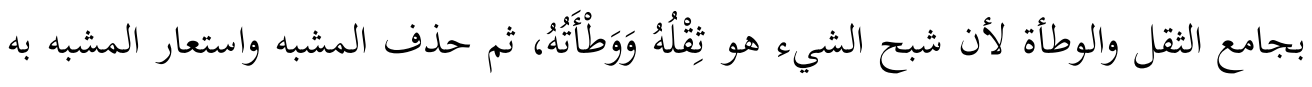
وهو (الاشباح ) للمشبه وهو (الظلام) على سبيل الاستعارة التصريحية، ثم شبه وصف الأشباح بالسائل يتبخر، وحذف المشبه به وذكر قرينتة وهي (تتبخر)، وأسندها للمشبه على سبيل

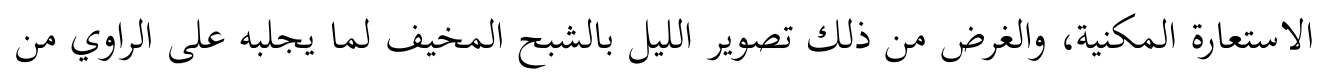
مخاوف وهموم، وهي استعارة ذات ارتباط بقاموس الأدب العربي، فقد ورد مثلها في معلقة امرىء القيس: (1) (n) وليلٍ كمَوجِ البحر أرخى سدولَه ::: عليّ بأنواع الهموم ليبتلي

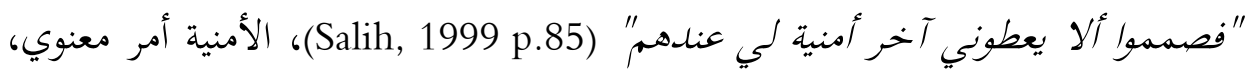
ولكن صالح وضعها في صورة شيء محسوس بقرينة (يعطوا)، وذلك على سبيل الاستعارة المكنية، وفي ذلك إشارة إلى الصرامة التي تعامل بها القضاة مع بطو بطل الرواية. 
Elrashid Yousif Mohamed Abbas

"هذه هي القوة التي تلبس قناع الرحمة" (Salih, 1999 p.86)، إنَّ كلمة( القوة)، وضعت

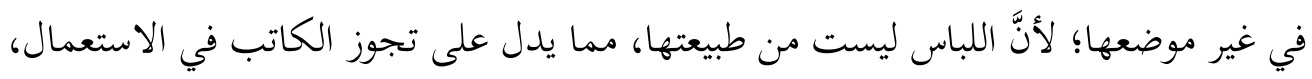
وأنه شبهها بمن تنطبق عليه هذه الطبيعة، وهو الإنسان ثم حذف المشبه به به وهو (الإنسان)

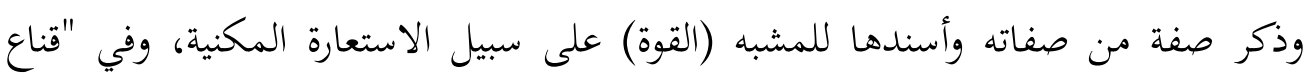
الرحمة" استعارة أيضا؛ حيث شبه الرحمة بامراة تتقنع بجامع الستر في كل، ثم حذف المشبه وله به وهي (المرأة) وذكر لازمًا من لوازمها وهي (قناع) واسندها للمشبه على سبيل الاستعارة المكنية.

"إنهم جلبوا إلينا جرثومة العنف الأوروبي" (Salih, 1999 p.117)، تشبيه العنف بمرض له

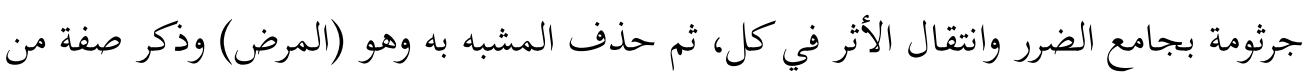
صفاته وهي (جرثومة) وأسندها للمشبه (العنف) على سبيل الاستعارة المكنية. وهذا التعبير

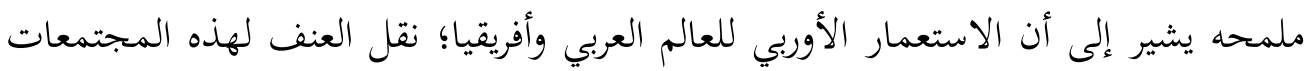
التي كانت آمنة ومسالمة.

"حتى يئن الحجر، ويبكي الشجر، ويستغيث الحلديل (135 p.139)

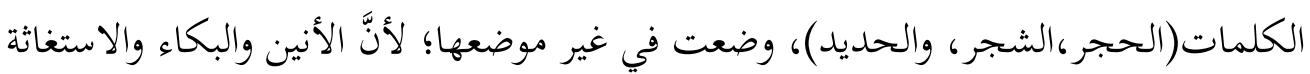

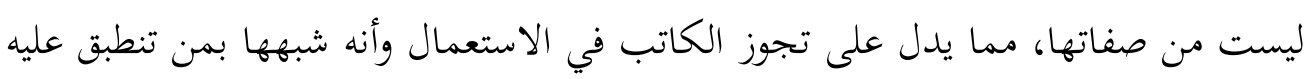

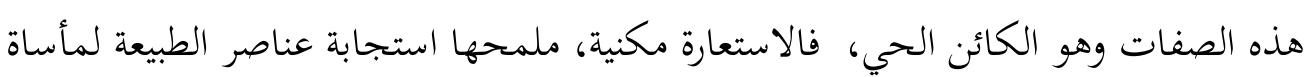
مصطفى سعيد.

"وسنخضع الشمس ذاتها لإرادتنا" (Salih, 1999 p.137)، في كلمة (الشمس) استعارة؛ لأن الخضوع ليس من طبيعتها، مما يدل على التجوز فى الاستعمال، وإنها شبهت بكائن لهادئ حي ينطبق عليه الخضوع، وفي ذلك ملمح على قوة إراداة الإنسان المُستعمَر في مقاومة كل

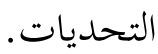

"حملت همي إلى جذع نخلة قريبة" (Salih, 1999 p.156)، الهم أمر معنوي ولكن الكاتب وضعه في صورة شيء حسي بقرينة (حملت)، وذلك على سبيل الاستعارة المكنية، وفي ذلك 
Elrashid Yousif Mohamed Abbas

إشارة إلى الهموم التي ألمت بالكاتب من وقع الجريمة التي ارتكبتها حسنة بنت محمود حين قتلت زوجها ثم انتحرت في ذات الوقت.

Salih, 1999 (كانت تلك لحظة من لحظات النشوة النادرة التي أبيع بها عمري كله

171.p.)، شبه صالح على لسان مصطفى سعيد النشوة بعملة يتقاضاها ثمنًا لعمره كله، كما

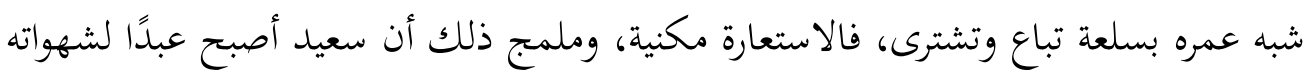
واستسلم لنزواته.

"وقد ظل مذاق تلك الليلة في فمي يمنعني من أي مذاق سواه" (Salih, 1999 p.183)، شبهت الليلة بشيء له طعم ومذاق وحذف المشبه به وجيء بشيء من لوازمه وهي كلمة

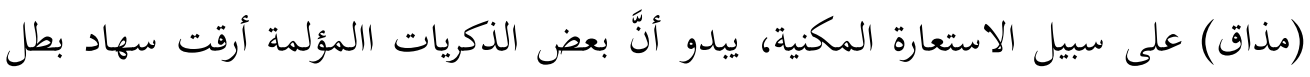
الرواية، وحرمته لذة النوم، ووقفت سدًا منيعًا صد عنه جميع الذكريات الحلوة.

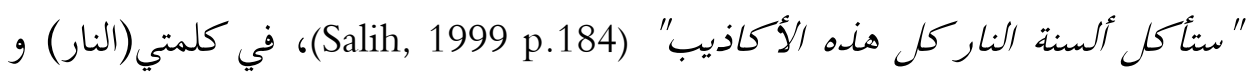
(الأكاذيب) استعارة مكنية، حيث شبهت الأولى (النار) بحيوان بقرينة (ألسنة)، وشبهت الثانبة (الأكاذيب) بشيء يمكن أكله، وملمح ذلك رغبة صالح في التخلص من كل ما يتعلق

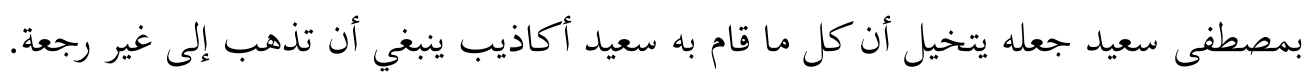

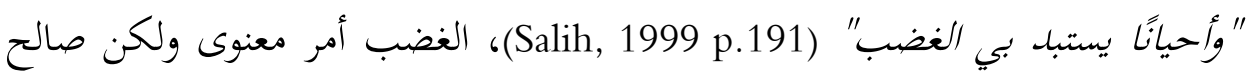
وضعه في صورة حسية بقرينة (يستبد)، فالاستبداد من طبيعة الإنسان، وهو المشبه به المحذوف، فالاستعارة مكنية، تشير إلى حال بطل الرواية (مصطفى سعيد) عند خلافه مع

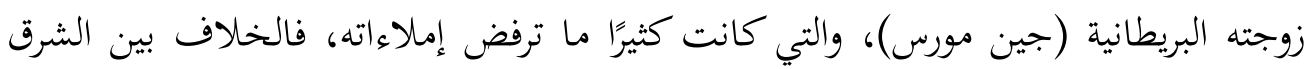
والغرب خلاف ثقافات، فالشرق المتخلف يضيق ذرعًا ويثور غضبًا من ثقافة الغرب المتحضر.

\section{الصور الكنائية في الرواية:}

الكناية في اللغة أن تتكلم بالشيء وتريد غيره. و في اصطلاح البلاغيين هي: لفظ أطلِقَ وأريد به لازم معناه الحقيقي مع قرينة تمنع من إرادة المعنى الأصلي مع المعنى المراد (Tha’ālibī, 1998) 
Elrashid Yousif Mohamed Abbas

أو طلب نفس الصفة، أو تخصيص الصفة بالموصوف، وهذا ما يحمل مضمون تقسيم البلاغيين الكناية إلى كونها عن: موصوف، أو صفة، أو نسبة بينهما (Hammouda, 1996). وباستقراء رواية صالح تاريخ ص. صيلمح الباحث أن صالح قد أفاد منها في نصوص روايته؛ ليضفي عليها مسحة جمالية، فضلا عن تأكيد معانيه وجعلها أشد، ويبدو ذلك في النماذج صناج التالية:

قال صالح على لسان جده وهو يتحدَّث إليهم: " أنني إذا جاوزت عمر النبوة فإنني

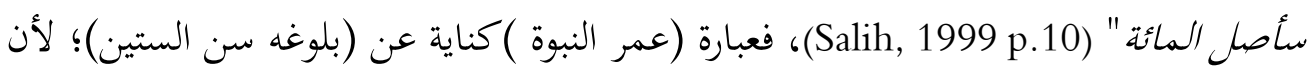
نبي الإسلام (ص) لم يعش فوق الستين كثيرًا، وفي هذه الكناية ملمح ديني أراده الكاتب على لى لى

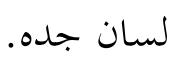

يقول: "ضحكوا برهة على حافة القبر" (Salih, 1999 p.105)، ويقول كذلك: "ملنا يا بني نسافر وحدنا في نهاية الأمر " (Salih, 1999 p.38)، فالعبارة الأولى وهي (حافة القبر) فيها كناية عن موصوف وهو ( قرب الأجل)، أما العبارة الثانية وهي(كلنا يابني نسافر وحدنا

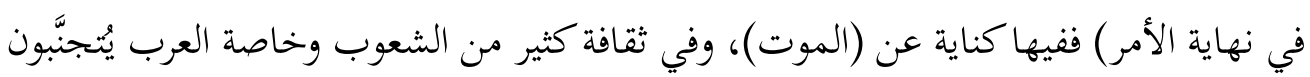
ذكر الموت صراحة،فالعرب تعبر عن الموت بعبارت مثل: الأجل المحتوم، المنية، هادم المبه

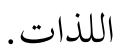

"وإنه يسارع بذراعه وقدحه في الأفراح والأتراح" (Salih, 1999 p.11)، كناية عن صفة وهي (مشاركة الآخرين)، إن مشاركة الناس في أفراحهم وأتراحهم بالنفس والمال والزاد عادة ولماد

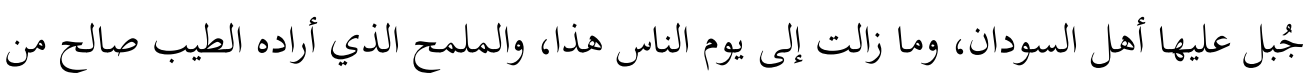

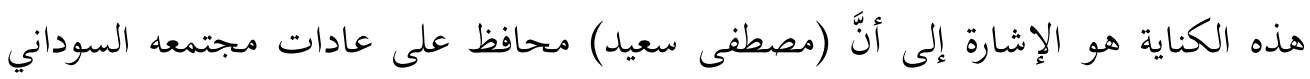
وتقاليده رغم أنه قضى شطرًا من حياته في أوربا التي تختلف عاداتها عن عادات أهل السودان.

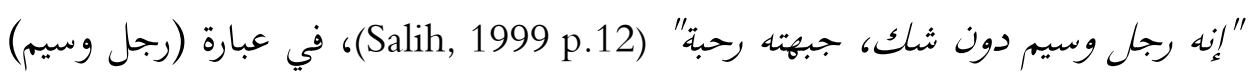

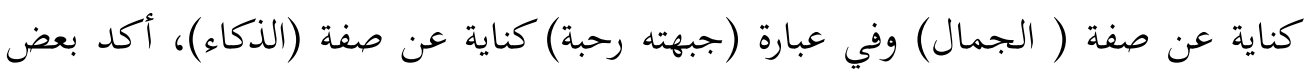

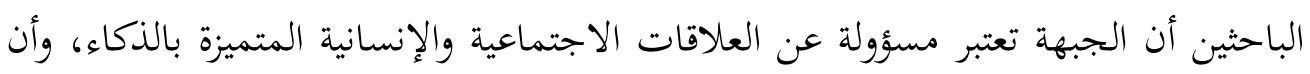


Elrashid Yousif Mohamed Abbas

في اتساعها دليل على تميز القدرات الذهنية والتفكيرية المتطورة خاصة في الميدان العملي

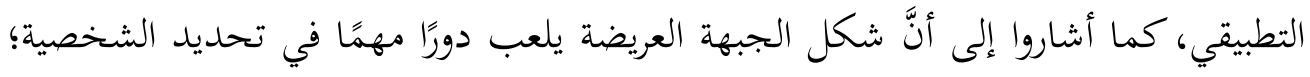

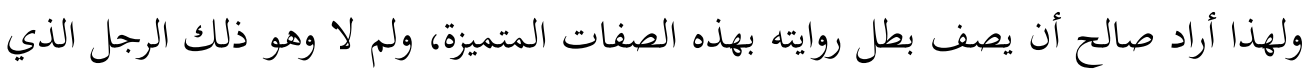

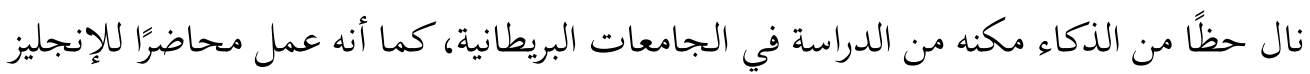

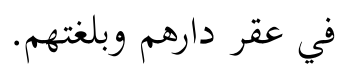

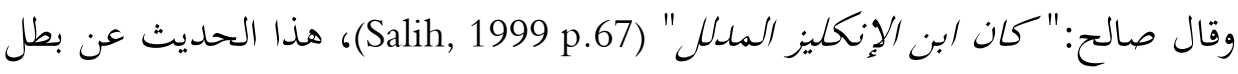
الرواية (مصطفى سعيد) وفيه كناية عن نسبة اهتمام الإنجليز به.

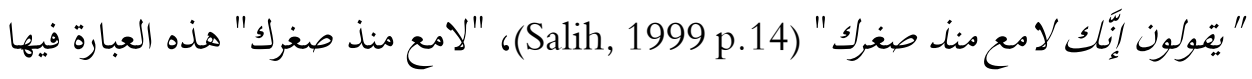

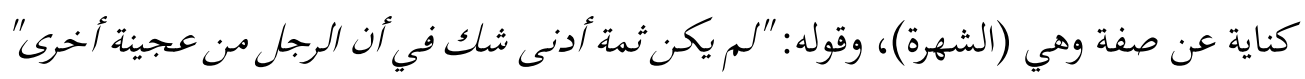

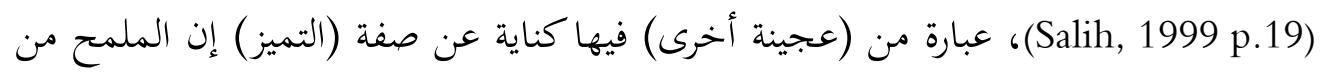
تلك الكنايات وغرضها هو لفت الأنظار إلى مصطفى سعيد ـ وإظهارة بطريقة يختلف فيها فيها

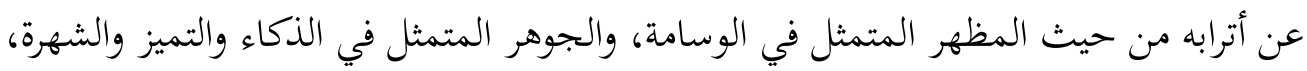

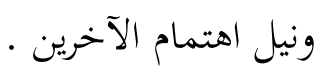

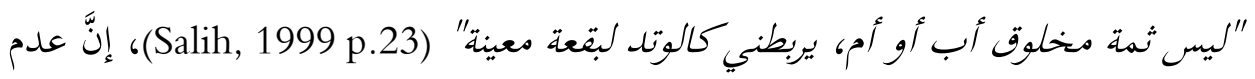

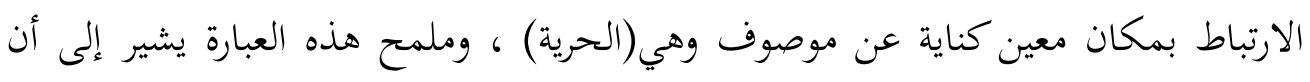

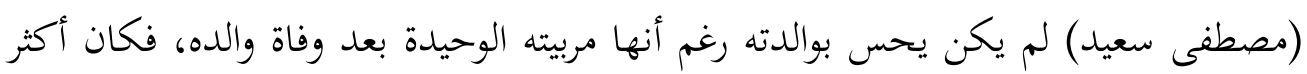
استقلالية وأقل عاطفة عن بقية الأطفال في سنه.

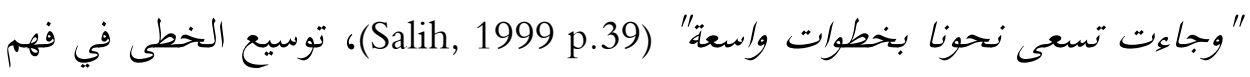

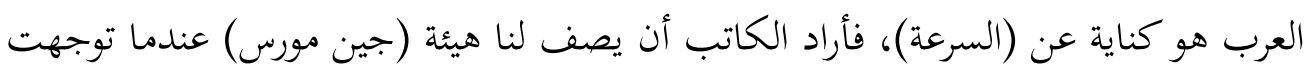

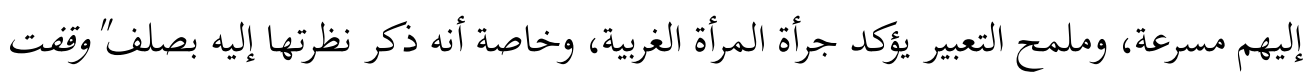

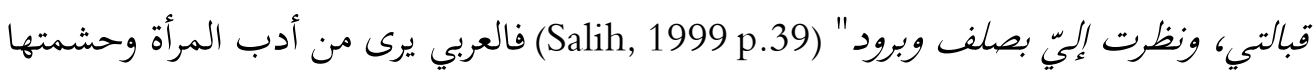

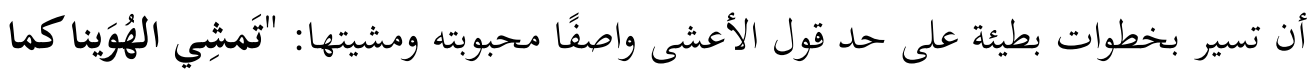

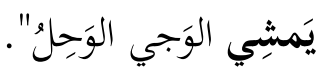


Elrashid Yousif Mohamed Abbas

"في تكوينك الروحي بقعة مظلمة" (Salih, 1999 p.69)، هذا التعبير كناية عن الحقد الذي وصف قاضي المحكمة البريطانية به مصطفى سعيد، خاصة وأنّه قد وجد رعاية خاصة من الإنجليز، ولكنه لم يرد الجميل بمثله بل فعل عكس ذلك.

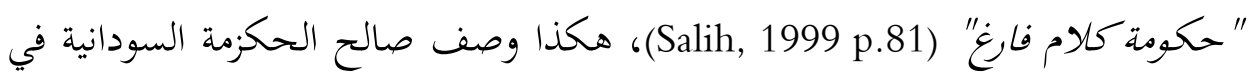
ذلك الوقت على لسان أحد أعمامه، وهذا الوصف يشير إلى ضعفها، وملمح ذلك يظهر أن صالح لم يكن مقتنعًا بأداء الحكومة في ذلك الوقت، وكذلك يكشف عن ارتباطه السياسي بييئته السودانية.

"والكفل إذا طوقته بذراعيك لا تصل حلده" (Salih, 1999 (93)، هذا القول فيه كناية عن صفة (البدانة)، وقد قاله ود الريس (واحد من شخصيات الرواية) في وصف فتاة من فتياة القرية، وملمح ذلك تفضيل الرجل الشرقي للمرأة البدينة الممتلئة لحمًا، والمرأة البدينة تمتاز بالرعونة والليونة وطيب الملمس، لذا قال هشام بن عبدالملك عن جاريته (ميمونة) وكانت (Al-Jawziyya, "بدينة: "لو أن رجلاً ابتلع ميمونة ما اعترض في حلقه منها شيء للينها (1982، والبدانة في المرأة من أهم مقاييس الجمال عند العرب، حيث إنهم كانوا يتعوذون بالله

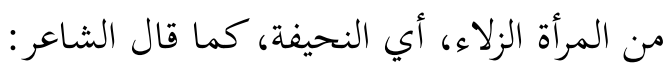
أعوذ بالله من زلاء ضاوية ::: كأن ثوبيها علقا على عود. "كانت العنز تأكل عشاءه" (Salih, 1999 p.94)، هكذا وصف بك بكري (أحد شخصيات الرواية)، ودالبشير (زوج بنت مجذوب) بهذه العبارة مكنيًا بها عن (ضعف ودالبشير وقلة حيلته)، ليدحض بها زعم (بنت مجذوب) التي قالت عنه: إنّه كان من أكثر أزوجها قوة، وقد

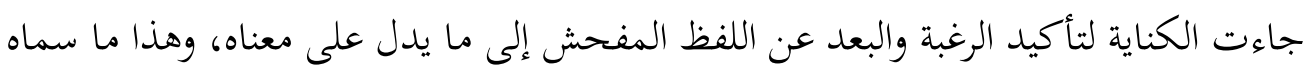
بعض اللغويين بالتلطف في الحديث أو لطف العبارة، وسماه الباحث عبقرية اللغة العربية في التعبير عن المحظور اللغوي.

"قالوا نسوان النصارى شيء فوق التصور" (Salih, 1999 p.99)، كناية عن (الجمال)، يقدم صالح من خلالها تصور المجتمعات الشرقية للمرأة في الغرب، بأنها تفوق نساء العالم 
Elrashid Yousif Mohamed Abbas

جمالاً، وخاصة أنّ هذه العبارة ذكرها صالح على لسان (ود الريس) الذي عُرف بخبرته في لي النساء وحمبّه لهن.

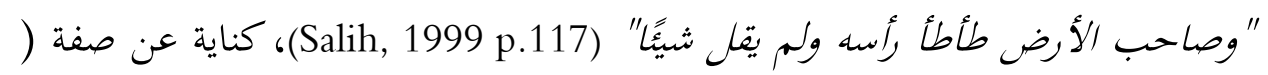
الذل والانكسار)، هكذا صور صالح حال محمود ود أحمد (بطل من المناهضين للاستعمار

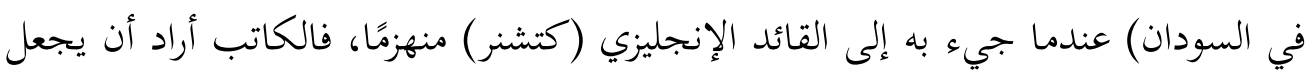

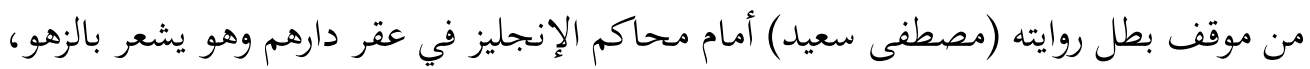

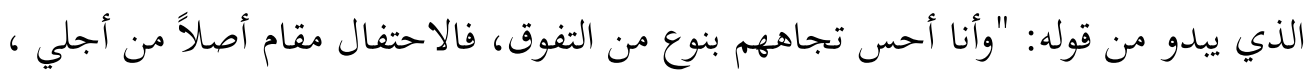

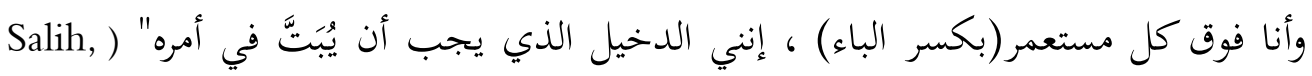
1999 p.117)، كأنه أراد أنهم يطأطئون روؤسهم عندما وقف أمام محكمتهم.

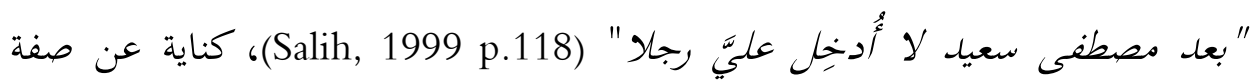

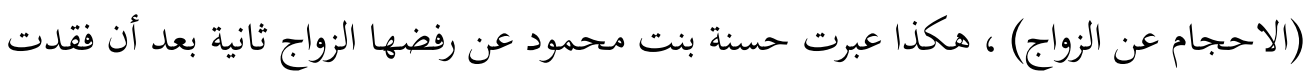

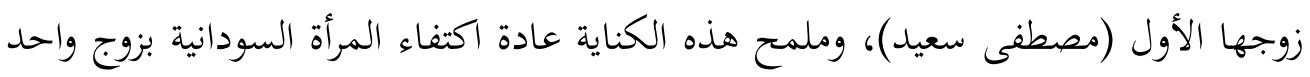

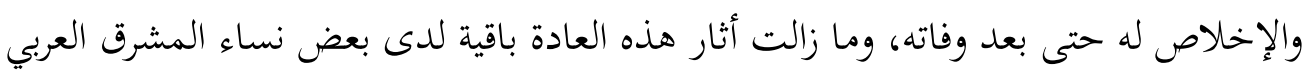

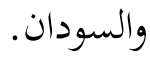

\section{الخلاصة}

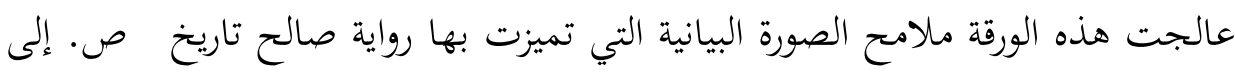

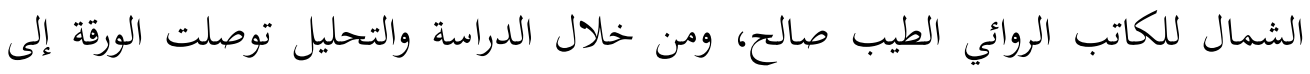

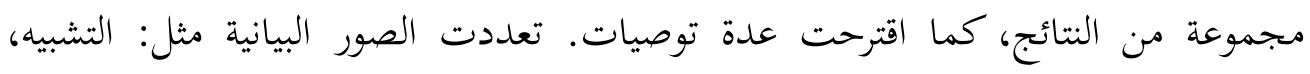

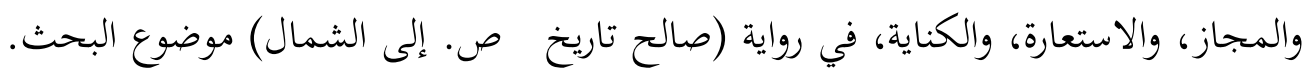

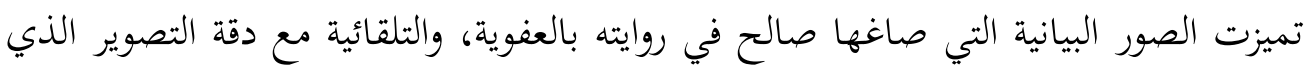

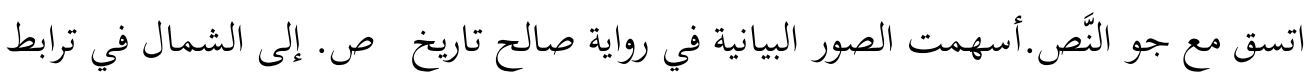

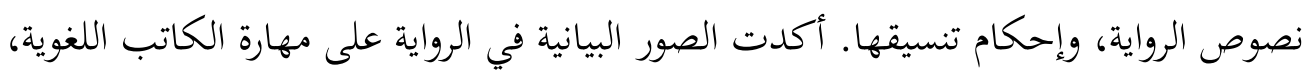

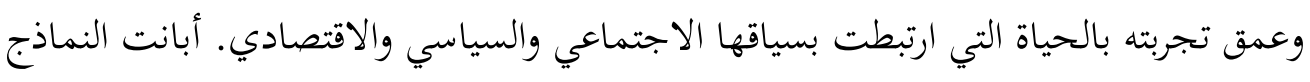


المستمدة من مادة البحث عند تحليلها عمق ارتباط الطيب صالح ببيئه الريفية التي نشأ في ربوعها، ذلك الارتباط الذي أثر في مضمون الرواية موضوع البحث. أثبتت نماذج البحث التي خضعت للتحليل والدراسة قدرة الرواية على عكس الحياة الاجتماعية التي ترتبط بتقاليد القرية.

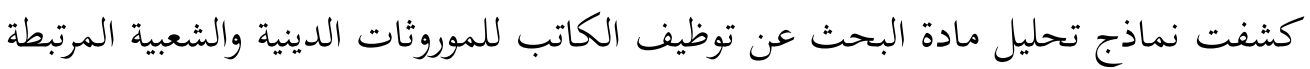
بحياة النَّاس في أدب الرواية.
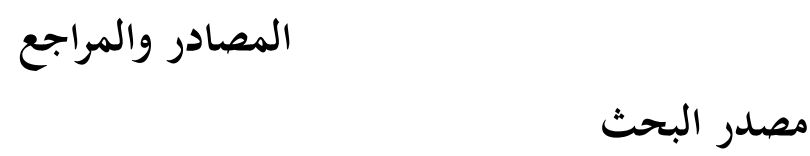

Salih, T. (1999). Mausim Al-Hiğraẗ Ila Al-Šamāl. Beirut: Dār Al-Ǧaīl LiNašr Wa-țabā'aẗ Wā-Taūzī' .

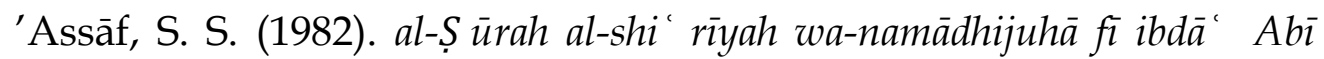
Nuwās. Beirut: Al-Mu'assä̈ al-ğ ā'iyyaä̈ liddirāsāt wa al-Našr. Al-Fayyā, A. A. (2010). Fì 'awālim Al-Ṭ ayyīb Ș āliḥ: Qirā'āt Naqdīyä̈ . Damascus: Dar Ninawa.

Al-Jawziyya, I. Q. (1982). Aṇ bār al-Nisā' (N. Riḍā, Ed.). Beirut: Dār Maktabä̈ al-Hayāë .

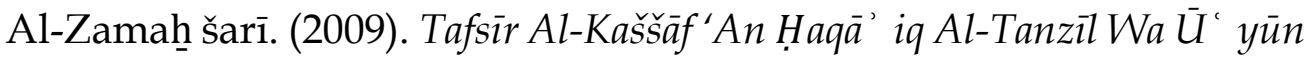
Al-'Aqāwyl Fì wuğ ūh Al-Ta'awyl. Beirut: Dar Marefah.

Albérès, R. M. (1982). Tārīh Al-Riwwāyä̈ Al-Hadīt ä̈ (2nd ed.; G. Sālim, Trans.). Beirut: Mansurat Bahr Al-Mutassit.

Alshami, H. R. (1998). Mar'ah fi al-riwayah al-Filastiniyah Dirasah 19651985. Damascus: Ittihad al-Kuttab Al-Arab.

Esmail, E. E.-D. (1981). Al-Ši'r al-'Arbì al-Mu'aș ir Qaḍāyāhu Wa Zawāhiruhu Al-Fanniyä̈ Wa al-Ma'nawiyaẗ (Vol. 3). Beirut: Dar Al- 
'Audah.

Hammouda, S. S. (1996). Durūs fì Al-Balāgàä al-'Arbìyä̈ . Iskandariya: Dar Maarifa al-Gamia.

Hibi, M. (2010). Al-Anā Wa Al' āhn ir Fī Riwāyyaẗ Mūsim Al-Hiğ rä̈ Ila Al-Šamāl. Retrieved April 2, 2021, from diwanalarab.com رواية_موسم-الهجرة-25378 Ibn Fāris. (2008). Mu'ğ am Maqāyis Al-Luggä̈ (A. M. Al-Šāmī, Ed.). Cairo: Dār al-ḥ adīt .

Ibn Kat īr. (1998). Tafsìr al-Qur'an Al-'Az ìm (Vol. 4; M. H. Shamsideen, Ed.). Beirut: Dar Al-kotob Al-Ilmiyah.

Ibn Manz ūr. (1993). Lisān al-' Arab (3rd ed.). Beirut: Dār Ș ādr Linšr.

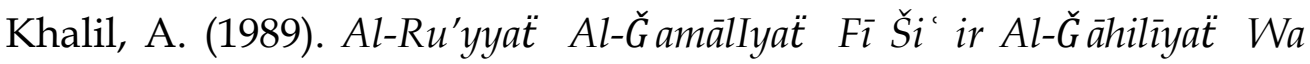
Sadr Al-Islām. University of Aleppo.

Qaș șāb, W. (2014). Al-Blāgăä Al-'Arbìyyaẗ : 'Ilm Al-Bayān. Damascus: Dar Al-Fikr.

Saeed, S. M. (2015). Al-Ṣ ùrä̈ Al-Bayāniÿ̈ Fì Sūrä̈ Yusūf. Al-Jazeera University.

Tha'ālibī, A. M. (1998). Al-Kināyä̈ wa Al-Ta'rīẹ (A. H. Farid, Ed.). Dar Qubbā' lil ț ibā'ä̈ Wa Al-Našr.

Wadi, T. (2014). Riwāyah Siyāsiyah. Giza: As-shirkah al-Misriyah alAlamiah lin Nasr - Longman.

Zaraziq, A. H. (2015). Term and the Narrative Term Their Hindrances in the Literary arabic Criticsm. Al-Ameed Journal, 4(14), 125-155. 